\title{
Empresa pública y consideraciones presupuestarias: una primera aproximación a la industria naval regional ${ }^{1}$
}

\author{
Cra. Paulina Emilia Rigo ${ }^{2}$
}

Esta versión: Diciembre 03 de 2015

\begin{abstract}
Resumen
El presente trabajo se propone analizar por primera vez desde el punto de vista de la administración financiera el desempeño de la industria naval regional, analizando en concreto el Astillero Río Santiago (ARS). Al mismo tiempo se consideran conceptos provenientes del campo de las Finanzas Públicas en relación al enfoque empresa pública versus privada.

Para ello, se analiza la Cuenta Ahorro Inversión Financiamiento (AIF) para los ejercicios 2006 a 2014, en base a los datos publicados por la Contaduría General de la Provincia de Buenos Aires. Luego, conforme al comportamiento observado en el ARS, se lo compara con otros entes similares.

Los resultados que se deprenden del análisis, son que el ARS opera en una situación deficitaria sostenida, cubierta por transferencias del gobierno provincial. Sobre la posibilidad de un funcionamiento presupuestario diferente existe evidencia de otras empresas públicas navales regionales que muestran un comportamiento inverso desde el punto de vista presupuestario al menos. De este modo, justificativos positivos (monopolio natural y sector estratégico) se contraponen con negativos (déficit presupuestario) a la hora de discutir el funcionamiento de dicha empresa pública.
\end{abstract}

Palabras Clave: Industria Naval, Empresas Públicas, Esquema Ahorro Inversión Financiamiento

Clasificación JEL: L12, H61, H63

\footnotetext{
${ }^{1}$ Este trabajo representa la tesis final de la Maestría en Finanzas Públicas Provinciales y Municipales de la Universidad Nacional de La Plata. La misma fue realizada bajo la dirección de Jorge Puig. La autora agradece los aportes de su director, de los participantes de los seminarios de avances de la Maestría, del Cdor. Raúl E. Zoia y del lector Joaquin Coleff. Errores u omisiones son de exclusividad responsabilidad de la autora.

${ }^{2}$ Email: rigopaulina@hotmail.com
} 


\section{Introducción}

En el campo de las finanzas públicas ha sido largamente estudiada la diferencia entre empresas públicas versus empresas privadas desde un punto de vista normativo. La divergencia de objetivos, los problemas de agencia y la coordinación de incentivos son, entre otros, algunos de los conceptos largamente tratados por la literatura teórica.

Sin embargo, a diferencia del normativo, el análisis positivo sobre el comportamiento de las empresas públicas en general se encuentra menos explorado y tampoco existe suficiente análisis sobre las cuestiones presupuestarias. Este déficit es bien marcado en Argentina y se vuelve más agudo si se focaliza sobre las empresas públicas asociadas a un sector específico como el naval.

En Argentina, la industria está integrada por pocos grandes astilleros dentro de los cuales pueden destacarse el Astillero Río Santiago (ARS) y Tandanor. Estas empresas presentan características de monopolio natural dada la presencia de economías de escala. El elevado costo unitario en que se incurre a los efectos de construir embarcaciones pesadas, requiriendo de una gran inversión y siendo los costos fijos muy altos suelen hacer que resulte preferible que una sola empresa construya buques. Así, en un monopolio natural, el costo de abastecer al mercado es mínimo al ser realizado por una única empresa. Ello es equivalente a una característica tecnológica denominada "subaditividad de costos": la provisión de la demanda se realiza con menores costos totales por una empresa que por medio de dos o más (FIEL, 1999).

Adicionalmente, la construcción naval es considerada un sector estratégico, de tradicional intervención estatal, con importantes efectos multiplicadores sobre otros sectores industriales. Esta industria produce bienes utilitarios de larga duración y alto valor agregado, es intensiva en uso de capital y su proceso productivo es no seriado y de ciclo largo. Dado el elevado nivel de agregación incorporado en los buques, la complejidad del proceso productivo y la utilización de componentes (insumos, equipos e instalaciones) provenientes de una amplia gama de sectores manufactureros, esta industria es considerada una actividad de síntesis. De acuerdo con las características de su producción, la construcción naval demanda mano de obra de alta calificación en diversos rubros, lo cual hace que los trabajadores de oficio ocupen un lugar central en el proceso productivo (Frassa, 2007).

Uno de los pilares fundamentales en que se apoya la industria naval pesada es la mano de obra especializada. La construcción y reparación de grandes embarcaciones requiere en general un diseño único que implica la participación determinante de profesionales, técnicos y obreros. (Frassa y Russo, 2012)

Ahora bien, estas cualidades de monopolio natural y de sector estratégico sumadas al costo de oportunidad de los recursos utilizados, no eximen a este tipo de empresas de una evaluación del desempeño presupuestario. Este aspecto también resulta trascendental para analizar la dinámica de los ingresos y de las erogaciones dado que el desempeño presupuestario de las empresas públicas suele afectar las finanzas del Sector Público.

En este contexto, este trabajo se propone analizar por primera vez positivamente el desempeño de la industria naval regional a través del Astillero Río Santiago (ARS), desde el punto de 
vista de la administración financiera (presupuestario). Para ello, se propone analizar la Cuenta Ahorro Inversión Financiamiento (AIF) para los ejercicios 2006 a 2014, en base a los datos publicados por la Contaduría General de la Provincia de Buenos Aires. Luego, conforme al comportamiento observado en el ARS, se propone compararlo con otros entes similares, para entender si el comportamiento del ARS es tradicional en este tipo de empresas o si por el contrario existen otros manejos presupuestarios.

Los resultados que se deprenden del análisis, son que el ARS opera en una situación deficitaria sostenida, cubierta por transferencias del gobierno provincial. Sobre la posibilidad de un funcionamiento presupuestario diferente existe evidencia de otras empresas públicas navales de la región que muestran un comportamiento inverso desde el punto de vista presupuestario al menos. De este modo, justificativos positivos (monopolio natural y sector estratégico) se contraponen con negativos (déficit presupuestario permanente) a la hora de discutir el funcionamiento de dicha empresa pública.

En lo que sigue el trabajo se organiza de la siguiente manera. La Sección 2 repasa el marco teórico en el cual se encuadra la temática. La Sección 3 describe el caso de estudio del ARS, mientras que la Sección 4 realiza una comparación con otras empresas similares de la región. Los comentarios finales de la Sección 5 cierran el trabajo.

\section{Marco teórico.}

En lo referente al tema de estudio hay dos enfoques: el enfoque Económico y el enfoque de la Administración Financiera. Esta sección se propone proveer una descripción detallada de cada uno.

\subsection{Enfoque Económico.}

El Enfoque Económico, se refiere a la teoría del principal-agente aplicado a las empresas públicas vs. privadas. La diferencia fundamental radica en los diferentes objetivos perseguidos por quienes actúan como principales en ambos tipos de empresas y en los distintos instrumentos disponibles que se corresponden con ellos (Garriga y Rosales, 2013).

En una empresa privada, el rol del principal corresponde a sus accionistas, quienes se supone tienen como objetivo maximizar el retorno financiero esperado, es decir, los beneficios intertemporales, reflejados en el valor del paquete accionario de la compañía. Por otro lado, el rol del agente corresponde al gerente o director de la empresa, cuyo objetivo puede ser distinto al del principal (por ejemplo, contiene como variables relevantes a la remuneración, el nivel de esfuerzo, la ubicación en la jerarquía, etc.). Asimismo, los accionistas no conocen con precisión cuales son las decisiones que toma el director de la empresa, con lo cual la relación se caracteriza por la existencia de una asimetría de información y una eventual discrepancia de objetivos. Esto hace posible que las decisiones tomadas en la empresa no se correspondan con los objetivos de los propietarios de la compañía (básicamente, la maximización del valor presente de los beneficios), reflejándose así 
entonces la divergencia entre propiedad y control. No obstante ello, los accionistas pueden imponer un esquema de incentivos al director de la empresa (por ejemplo, pagándole parte de su salario en acciones de la firma, las que serán más valiosas si los beneficios presentes y futuros son mayores; despidiéndolo si su comportamiento no es satisfactorio, etc.) de forma tal que sus decisiones respeten en buena medida los intereses de los primeros.

En una empresa pública, por otro lado, el principal es el gobierno, y el agente es el director. Además, existe una relación principal- agente precedente, ya que son los individuos (en su rol de votantes) los que delegan la tarea al gobierno, en cuyo caso se tiene: principal = votantes; agente = gobierno, con lo cual, considerando ambos niveles de delegación, la relación sería: votantes gobierno - director.

Comparativamente con la empresa privada, las diferencias más obvias en la relación principal-agente en las empresas pública consisten en que el objetivo del principal no consiste en la maximización de beneficios, sino que coexisten distintos objetivos al fijar el funcionamiento de una empresa pública, tales como: la maximización del superávit del consumidor, la provisión de empleo, el desarrollo de proveedores Pymes, la estabilidad de precios, etc., lo que en general se denomina "maximizar la función de bienestar social", muchas veces de definición ambigua. En las empresas públicas, la utilización discrecional de instrumentos para incentivar la acción de los directores es más sospechosa y resistida por los votantes, pues se desconfía que el objetivo final perseguido por el principal (el gobierno) sea favorecer sus propios intereses y no los de los votantes. Así, al estar los derechos de propiedad peor definidos y ser más ambigua la medición del "resultado" en las empresas públicas que en las privadas, la posibilidad real de vincular premios con resultados (o sea, de otorgar incentivos) es mucho menor.

Como la delegación de tareas no se da, en general, en un marco de incentivos, se descansa en mayor medida en la supervisión de las acciones del agente. Una forma usual de ejercer esta supervisión consiste en multiplicar el número de relaciones jerárquicas dentro del sector público, lo que da lugar a organizaciones "burocráticas". (Garriga y Rosales, 2013)

Una de las grandes preocupaciones del funcionario de una empresa pública es que se crea que su trabajo puede hacerse con un costo menor. El funcionario que no gasta todo su presupuesto corre el peligro de verlo reducido al año siguiente, lo cual da lugar a los problemas de tener que agotar el presupuesto aprobado por el Parlamento antes de que finalice el año fiscal. (Stiglitz, 1995)

El funcionario no solo puede enmascarar los beneficios y los costos de sus actividades; también puede emprender acciones que influyan en ellos. Normalmente los organismos oficiales reciben un presupuesto general, que es el principal instrumento que se usa para controlarlos. Sin embargo, gozan de una cierta discreción dentro de ese presupuesto. El funcionario puede valerse de esta discreción para perseguir sus propios objetivos y no los fijados por los legisladores. Los organismos públicos recurren a veces a la amenaza del recorte de una parte de los gastos para aumentar sus presupuestos. (Stiglitz, 1995)

En lo que respecta a los incentivos, las empresas públicas, tienen incentivos diferentes tanto organizativos como individuales. Algunas de las diferencias se deben a que no existen ni competencia ni la posibilidad de quiebra. La posibilidad de quebrar es importante; limita la magnitud 
de las pérdidas sociales que puede generar una gestión ineficiente en una empresa privada y es un mecanismo natural para sustituir a los equipos directivos ineficientes. Impone una restricción presupuestaria a las empresas. En cambio, las empresas públicas incurren frecuentemente en grandes déficit durante largos períodos. La posibilidad de obtener subvenciones del Estado ha hecho que los directivos de las empresas públicas opongan menos resistencia a las demandas salariales de los sindicatos; en muchos países, los salarios de las empresas públicas son muy superiores a los que perciben los trabajadores semejantes del sector privado ${ }^{3}$.

Otra diferencia entre empresas públicas y privadas es la ausencia de competencia en las primeras. La competencia desempeña varios papeles importantes. En primer lugar, permite elegir. Cuando hay competencia, los consumidores pueden revelar sus preferencias eligiendo, lo que obliga a las empresas a hacer frente a los costos que impone la burocracia a los consumidores. La competencia frena y limita las ineficiencias en las que incurren las empresas públicas. Proporciona una estructura de incentivos: las empresas competitivas, en su intento de elevar sus ventas, tratan de encontrar la combinación de servicios que mejor satisfaga las necesidades de sus clientes. La competencia permite establecer comparaciones: cuando hay varios organismos que realizan actividades parecidas, existe una base para hacer comparaciones. Si un organismo tiene un costo más bajo que otro, cabe preguntarse el por qué de la diferencia. Aun cuando dicha comparación no se realice explícitamente, es realizada implícitamente por el mercado y se refleja en la rentabilidad de la empresa. La competencia implica que las empresas que son eficientes y capaces de suministrar los tipos de bienes y de servicios que desean los consumidores crecen y se expanden; y las que son ineficientes decaen.

En cuanto a los incentivos individuales, otra importante diferencia entre empresas públicas y privadas se encuentra en las estructuras de incentivos que tienen los trabajadores del sector público. Restricciones de la estructura salarial, los directivos de las empresas públicas raras veces tienen estructuras retributivas estrechamente relacionadas con los beneficios, como ocurre en las grandes empresas privadas. La estabilidad en el empleo, la segunda diferencia importante es la facilidad con la que pueda despedirse a los empleados. Es muy difícil ser despedido de un empleo público. De hecho, esta seguridad es citada a menudo por los empleados potenciales como uno de los rasgos más atractivos del sector público. La dificultad de aumentar las retribuciones según el buen rendimiento, unida a la ausencia de castigos por el bajo rendimiento, explican en gran medida la conducta burocrática. (Stiglitz, 1995).

${ }^{3}$ En la Argentina y en América Latina, desde el año 1992 hasta el año 2012, los ingresos de los empleados públicos se mantuvieron por encima de los ingresos de los trabajadores en el sector privado. Por ejemplo, en el año 2012 un trabajador del sector público obtuvo un ingreso laboral promedio de U\$S 1.010,00 mientras que un trabajador del sector privado formal percibió un ingreso laboral real de U\$S 910,00 (Gasparini, Arcidiácono, Carella, Puig, Gluzmann, Brassiolo, 2015) 


\subsection{Enfoque de la Administración Financiera.}

Por otro lado, el enfoque de la Administración Financiera de acuerdo a lo que establece el Manual de Transparencia Fiscal (2007) del Fondo Monetario Internacional, las buenas prácticas de transparencia fiscal, consisten en: una clara definición de funciones y responsabilidades, contar con procesos presupuestarios transparentes, acceso del público a la información y garantías de integridad.

Una clara definición de funciones y responsabilidades, requiere que el sector gobierno se distinga del resto del sector público y del resto de la economía. Asimismo, dentro del sector público, las funciones de política y administración deberán ser claras y divulgarse al público.

El marco jurídico, normativo y administrativo establecido para la gestión de las finanzas públicas debe ser claro y transparente.

En cuanto a los procesos presupuestarios transparentes, la elaboración del presupuesto deberá respetar un calendario establecido y regirse por objetivos de política macroeconómica y fiscal claramente definidos. Y deberán establecerse procedimientos claros para la ejecución, supervisión y declaración del presupuesto.

En lo referente al acceso del público a la información, deberá proporcionarse al público información completa sobre las operaciones fiscales pasadas, actuales y futuras, y sobre los principales riesgos fiscales. La información fiscal deberá presentarse de manera que facilite el análisis de las políticas y que estimule la rendición de cuentas. Deberá contraerse el compromiso de divulgar puntualmente información sobre las finanzas públicas. El requisito básico de este principio tiene por objeto garantizar lo siguiente: existe la obligación legal de publicar puntualmente información fiscal.

Las garantías de integridad, implican que los datos fiscales deberán cumplir las normas generales aceptadas sobre la calidad de los datos. Las actividades fiscales deberán estar sujetas a una supervisión y a salvaguardias eficaces de carácter interno. La información fiscal deberá someterse a examen externo.

\section{Caso de estudio}

\subsection{Descripción general}

Tradicionalmente, la industria naval, aunque con matices según los países, ha sido apoyada por una política estatal de subsidios, créditos y beneficios impositivos, tanto para las empresas armadoras como para los astilleros. Este conjunto de medidas hicieron de esta industria una actividad fuertemente subvencionada en todo el mundo. (Frassa y Russo, 2012)

El apoyo estatal a la construcción y reparación de buques en Japón, Corea del Sur, Brasil, Singapur, Portugal, España, Francia, Países Bajos, Noruega, Finlandia, Vietnam y China mostró que tal aspecto es vital para el desarrollo de esta industria. En muchos casos, los Estados fueron (y son) productores directos y/o reguladores de la actividad industrial por razones, inicialmente, de 
nacionalismo o soberanía económica. Esta intervención se ha desarrollado mediante la financiación directa a empresas públicas y la aplicación de subsidios a través de préstamos, subvenciones $u$ otros incentivos financieros (incluyendo impuestos), entre otras medidas. (Barbosa Pereira y Frassa, 2013)

Las empresas estatales de cada país son las generadoras de la principal demanda del sector. Argentina perdió la demanda proveniente de dichas empresas al producirse la privatización de las mismas en los años 1990. (Versino, Frassa, Guedes de Jesus y De Gitahy, 2010)

En Argentina, el desmantelamiento de los mecanismos de financiamiento del Estado a esta industria y la falta de una política de inversión y renovación tecnológica, sumado a la caída de la demanda interna, imposibilitan crecimiento sostenible y a largo plazo de la industria naval. La nacionalización de la petrolera YPF en el año 2012 inaugura una nueva etapa para la industria nacional, pero aún no se tradujo en políticas de articulación concretas para el caso de la industria naval. (Barbosa Pereira y Frassa, 2013)

El sector es considerado estratégico tanto por cuestiones vinculadas a la seguridad nacional como por sus implicancias en el desarrollo económico y el crecimiento industrial. (Versino, Frassa, Guedes de Jesús y De Gitahy, 2010)

La experiencia de crecimiento de algunas economías del sudeste asiático, muestra a la actividad naval como un sector estratégico en el proceso de desarrollo y por tanto sus gobiernos adoptan las medidas necesarias para el crecimiento de dicha industria. (Mauro, 2011)

Los países asiáticos se han especializado en la producción a gran escala de las embarcaciones más demandadas (graneleros, petroleros, etc.) y Europa en la producción de equipos/componentes con alto contenido tecnológico. Los principales países productores de buques son: China, Corea del Sur y Japón.

China, país en el cual las corporaciones navales son propiedad del Estado, es el líder actual en la industria naval gracias a la decisión gubernamental de definir al sector como estratégico y en consecuencia implementar un conjunto de medidas tendientes a estimular la construcción de embarcaciones por parte de los astilleros chinos, inicialmente para abastecer el mercado interno y más recientemente para alcanzar también el mercado mundial. Estas acciones están orientadas al desarrollo de innovaciones y mejora de las instalaciones por parte de los astilleros, el aprendizaje a través de la asociación con firmas líderes en el mundo, al financiamiento de la fabricación de buques en astilleros nacionales, a la protección comercial del mercado interno frente a la importación y a la promoción de las exportaciones de barcos construidos en China. (Mauro, 2011)

La situación político- económica del mundo luego de la Primera Guerra Mundial (1914 a 1917), incrementó el comercio y el transporte de materias primas exportables como así también se intensificó la defensa de la posición estratégica de Argentina con relación a su soberanía.

El 17 de diciembre de 1934 se creó la Comisión de la Marina Mercante, lo que dio impulso a un plan específico e integral de construcciones navales que se llevarían a cabo posteriormente en Puerto Belgrano, Tigre, San Fernando y fundamentalmente en Río Santiago, Ensenada, Provincia de Buenos Aires.

La entonces Marina de Guerra ordenó la construcción de nueve rastreadores Parker, los cuales deberían desarrollarse íntegramente en el país. Ante ello, se utilizaría un astillero que 
condujera todo el operativo, del que saldrían los planos, las directivas, los equipos y materiales necesarios.

Toda la dinámica que provocó esta nueva impronta en la construcción naval a partir de la formación total del elemento humano especializado en su mano de obra, más el impulso institucional a partir de sus resultados, desembocó en la decisión de establecer un gran astillero para construcciones navales militares y los Talleres Generales de la Base Naval de Río Santiago, fueron la base para lo que hoy es Astillero Río Santiago (ARS)

Al mismo tiempo que se avanzaba en la construcción del astillero, se intensificaba la formación de nuevo personal y el perfeccionamiento del existente en todos los niveles y especialidades con vistas al futuro (operarios, técnicos, trazadores, dibujantes, ayudantes de laboratorio, almacenista, etc.). El paso más importante en cumplimiento de aquella finalidad fue la creación de una escuela de artesanos.

El ARS era un establecimiento industrial en poder del Estado que funcionaba con un régimen de trabajo acorde a los parámetros de una gran empresa industrial. Ante ellos, por Decreto 10.627 del Poder Ejecutivo con fecha del 15 de junio de 1.953 se creó Astilleros y Fábricas Navales del Estado (AFNE), empresa integrada por el Astillero Río Santiago (ARS) y por la Fábrica Naval de Explosivos Azul (FANAZUL), con dependencia del Ministerio de Marina.

Ubicado en la ciudad de Ensenada, provincia de Buenos Aires, sobre el Río Santiago, el ARS comprendía en aquel entonces unas 229 hectáreas y 55 áreas productivas.

Cuando se completó su construcción, el ARS contaba ya con talleres de calderería, herrería, mecánica con dos centros de mecanizados únicos en aquel momento en el país, cobrería, estructuras, electricidad, fundición de hierro y acero especiales, carpintería de blanco y de ribera, además de las grúas en gradas y muelles, playas de materiales, central de fuerza (usina eléctrica, vapor, aire), dique y grúa flotante, almacenes, vestuario, comedor, escuela de aprendices, entre otros sectores de particular operatividad.

En 1969 modifica su forma societaria y pasa a ser una Sociedad Anónima del Estado.

A mediados de la década del '70, sus principales clientes eran la Armada Nacional, la Empresa de Líneas Marítimas Argentinas (ELMA) y Yacimientos Petrolíferos Fiscales (YPF), además de la multiplicidad de las actividades que comenzaron a desarrollarse en grandes obras metalmecánicas y componentes de magnitud para diferentes obras y empresas, tanto nacionales como internacionales.

Contaba con una planta de aproximadamente 5.500 empleados y alrededor de 3.000 contratados por distintas empresas subcontratistas afectados a la producción directa.

En la década del ' 80 se realizaron grandes construcciones navales.

En agosto de 1993 por el Decreto 4538, el Astillero salió de la órbita del Ministerio de Defensa de la Nación y pasó a depender de la Provincia de Buenos Aires.

En 1995 se aprueba la instalación de la Zona Franca de La Plata en el predio que hasta entonces pertenecía al astillero, dejándolo en posesión de sólo 23 de sus 229 hectáreas originales. Esta medida provocó la pérdida de numerosas instalaciones y equipos con la consiguiente reducción de su capacidad instalada. Asimismo, el ajuste en el presupuesto provincial implicó, para la empresa, 
la obsolescencia de su maquinaria por falta de reemplazo, el congelamiento de la planilla de trabajadores y la escasez de recursos financieros para emprender nuevas obras. (Frassa y Russo, 2012)

La instalación de una zona franca en el territorio de la empresa permitió al gobierno obtener ganancias comerciales en un espacio que era improductivo. Los beneficios que obtenía así el gobierno provincial tenían el costo de subvencionar económicamente al astillero. (Frassa, Muñiz Terra y Naclerio, 2009)

En el año 2006 se recuperó sólo parte de ese territorio y con ello áreas indispensables para la producción, como talleres y playas de trabajo.

Hoy en día el Astillero Río Santiago, es un organismo descentralizado dependiente del Ministerio de la Producción, Ciencia y Tecnología de la Provincia de Buenos Aires. Sus principales objetivos de esta entidad autárquica de derecho público son el fiel cumplimiento del convenio suscripto el 26 de agosto de 1993, mediante el cual el gobierno nacional transfirió a la provincia de Buenos Aires el personal y los activos de Astilleros y Fábricas Navales del Estado S.A.; y el desarrollo, explotación y comercialización de las actividades propias y conexas de la industria naval, pudiendo realizar además cualquier otra actividad dentro de las industrias metálicas básicas y en general, maquinarias y equipos, y los respectivos complementos inherentes a dichos rubros.

El organismo en cuestión, se rige por la Ley de Administración Financiera N" 13.767 y su Decreto Reglamentario 3260/08, la Ley de Contabilidad de la Provincia de Buenos Aires, Decreto Ley $N^{\circ} 7764 / 71$, y su Reglamento de Contrataciones, Decreto $N^{\circ} 787 / 04$. Los organismos de contralor del Ente son la Contaduría General y el Honorable Tribunal de Cuentas de la Provincia de Buenos Aires.

Las áreas de producción consisten en: construcciones navales, cuyos objetivos comprenden las tareas de planificación, proyecto y construcción de todo material flotante, entre los cuales se incluyen: buques mercantes, buques militares, remolcadores, barcazas, plataformas off-shore y compuertas (este programa cuenta con 1355 cargos de personal de planta para su gestión operativa); reparaciones navales, que consisten en trabajos de reparación de artefactos navales realizados a flote y/o en dique seco. Comprende las tareas realizadas en el casco, alistamiento, maquinarias y equipos (este programa cuenta con 60 cargos de personal de planta para su gestión operativa); y metal-mecánicas, cuyo objetivo consiste en la fabricación de estructuras metálicas, equipos y maquinarias (este programa cuenta con 100 cargos de personal de planta para su gestión operativa).

La Dirección Ejecutiva y Conducción Superior, efectúa acciones presupuestarias de dirección, control y apoyo a la gestión productiva, de carácter instrumental y que afectan a todos los programas y a la provisión de bienes y servicios del ARS (este programa cuenta con 780 cargos de personal de planta).

Los trabajadores del ARS se encuentran afiliados a la Asociación de Trabajadores del Estado (ATE), que forma parte de la organización nacional Central de Trabajadores Argentinos (CTA) desde su creación en 1992. A nivel regional, el ARS pertenece a la seccional de ATE Ensenada, cuya dirección ha estado tradicionalmente en manos de los delegados del astillero. 
En cuanto a la estructura orgánica, el ARS cuenta con: un presidente, un gerente general, sub gerente general y diez gerencias: gerencia técnica, gerencia de abastecimiento, gerencia de administración, de asuntos jurídicos, gerencia comercial, gerencia de relaciones industriales, gerencia de producción, gerencia de recursos humanos, gerencia de control de calidad y gerencia unidad directiva proyecto energía renovable.

Actualmente, existen restricciones para la ejecución del presupuesto de erogaciones, las cuales se traducen en la asignación de exiguos cupos mensuales por parte del Ministerio de Economía de la Provincia de Buenos Aires.

EI ARS es una empresa de producción que impacta positivamente en la economía real local, dado: el empleo directo e indirecto, cuenta con una nómina de 2.295 cargos de personal; en cuanto a la capacitación, posee una escuela técnica privada de fábrica reconocida por la Dirección General de Cultura y Educación de la Provincia de Buenos Aires tendiente a la formación de recursos humanos para la industria naval; en lo referente a sus capacidades, tiene capacidad para construir buques militares, buques mercantes de hasta 80.000 TN. Para el ejercicio 2015, implementó una unidad de negocio dedicada a las energías renovables cuyo objetivo es desarrollar un proceso de fabricación seriado en escala de componentes para aerogeneradores de alta potencia, tales como turbinas y estructuras de torres eólicas. Se adquirió un moderno centro de mecanizado con un subsidio otorgado por el Fondo Argentino Sectorial (FONARSEC) de la Agencia Nacional de Promoción Científica y Tecnológica. Permitirá fabricar un total de 120 torres en un plazo de tres años.

\subsection{Condiciones económicas del sector}

Además de tener como principales clientes en el pasado a la Armada Argentina, a la Empresa de Líneas Marítimas Argentinas (ELMA) y a Yacimientos Petrolíferos Fiscales (YPF), el ARS fabricó para la empresa nacional Trans Ona una embarcación remolcadora y un buque petrolero. Para el armador alemán Wilhem Finance Inc. construyó cinco buques graneleros.

En cuanto al área metal mecánica, se construyó en el ARS la estructura metálica del Teatro Argentino de La Plata, las réplicas de las cruces de coronamiento de la Basílica de Luján. El ARS se encargó del diseño y fabricación de los nudos y de las estructuras metálicas, de la ingeniería y dirección del montaje del techo del Estadio Único Ciudad de La Plata. También se fabricaron en el ARS, piezas para centrales hidroeléctricas como Yacyretá, Los Reyunos, Salto Grande y Tocoma. Se llevaron a cabo grandes obras de infraestructura para caminos.

Actualmente, el ARS tiene como clientes a la empresa PDVSA de la República Bolivariana de Venezuela, para quien está construyendo el segundo buque productero "Juana Azurduy" de 47.000 toneladas, a las empresas nacionales Abadía del Mar y Whitesea Argentina S.A. Recientemente y después de 32 años del último trabajo para YPF, el ARS finalizó la fabricación de cuatro pontones de contención de combustible. Se trata de artefactos flotantes que se amarran entre el muelle y el buque al momento de carga y descarga de producto y sus derivados a los efectos de prevenir accidentes que puedan afectar el medio ambiente. 
Por otro lado, se está fabricando una compuerta de toma para un vano de una unidad hidrogeneradora para la central hidroeléctrica de Salto Grande, ubicada en Entre Ríos, para la Comisión Técnica Mixta de Salto Grande (CTM).

En cuanto a reparaciones, la Armada Argentina y la empresa Buquebus realizan en el ARS el mantenimiento y las reparaciones necesarias de su flota.

EI ARS comenzará a mecanizar los primeros componentes de aerogeneradores de alta potencia, tales como turbinas y estructuras de torres eólicas.

Para la Armada Argentina, se fabricarán dos lanchas para la instrucción de cadetes.

El ARS es el único astillero del país que se encuentra en condiciones de construir buques militares desde destructores de gran porte hasta lanchas rápidas, buques mercantes, marítimos y fluviales de hasta 80.000 toneladas de porte bruto. También puede fabricar construcciones off shore y plataformas de todo tipo. En cuanto a reparaciones, puede reparar embarcaciones de gran porte y tiene como competidor en la región a Tandanor. $Y$, también, es la única empresa del país en condiciones de construir puentes metálicos viales.

El sector enfrenta una demanda derivada del nivel de actividad y rentabilidad de otros mercados (transporte, pesca, petróleo, servicios de defesa y seguridad, investigación, turismo, etc. Esto se evidencia en el caso del petróleo, ya que tanto la empresa petrolera venezolana PDVSA como Yacimientos Petrolíferos Fiscales (YPF) son clientes del ARS. En cuanto al turismo, la empresa Buquebus confía en el ARS la reparación de sus embarcaciones.

\subsection{Condiciones organizacionales del ARS}

Los problemas de agencia que se evidencian en el ARS son entre el gobierno de la Provincia de Buenos Aires y el presidente del ARS por ejemplo. En este caso, el gobierno sería el principal y el presidente del ARS el agente. Además, existe una relación principal-agente anterior, en la cual, los votantes sería el principal y el agente el gobierno.

Otras relaciones principal-agente son entre el presidente del ARS y los gerentes y entre estos y los empleados. Entre el presidente del ARS y el sindicato, y entre éste y los trabajadores se configuran otras relaciones de agencia.

En cuanto a los incentivos en el ARS, éste cuando bota un barco abona a toda su nómina de personal un premio por botadura, teniendo en cuenta para su cálculo y liquidación el total de toneladas del buque en cuestión. Por otro lado, en el ARS no es común que existan castigos por bajo rendimiento. Hay una fuerte presencia sindical que impide que esos castigos se hagan efectivos.

El hecho de que los salarios en las empresas públicas actualmente sean superiores a los que perciben los trabajadores semejantes del sector privado, está relacionado con el alto nivel de sindicalización de los trabajadores y la importancia otorgada por ende a las paritarias, en el caso del ARS.

Actualmente, en el ARS existe una política de trabajo en conjunto entre las autoridades de la empresa y las autoridades gremiales.

Por otro lado y en cuanto a las contrataciones del ARS para adquirir los bienes y servicios que demanda su proceso productivo, el importe de la contratación en cuestión determina si se trata 
de una licitación pública, privada o de una contratación directa. Cuando el importe de la contratación se encuentre entre $\$ 128.000,00$ y $\$ 1.200 .000,00$ se debe realizar una licitación privada. Si el importe es inferior a $\$ 128.000,00$, corresponde realizar una contratación directa en determinados casos expuestos en la Ley de Contabilidad.

Cuando el importe de la contratación supere $\$ 1.200 .000,00$ se debe llevar adelante una licitación pública, la cual consta de tres etapas: una autorización del llamado, una etapa precontractual (pre-adjudicación y adjudicación) y una etapa contractual (perfeccionamiento del contrato y ejecución). En la etapa de autorización del llamado, se efectúa una programación de las contrataciones a los efectos de evitar la existencia de desdoblamientos en las mismas. Toda autorización a un llamado deberá fijar obligatoriamente la imputación preventiva del gasto y dejar expresa constancia de la fecha e instancia competente que autorizó el último llamado para seleccionar el bien o servicio similar requerido. Igual constancia respecto de la fecha y autoridad que aprobara la última contratación. En la etapa pre-contractual, se publicitará la licitación pública mediante avisos en el boletín oficial de la provincia de Buenos Aires, en el sitio web de la provincia y en un diario. Dichos avisos deberán cumplimentar ciertos requisitos. Sin perjuicio de los mismos, se invitará como mínimo a diez firmas del ramo que se licite, inscriptas en el Registro de Proveedores y Licitadores. Los procedimientos de contratación se regirán por: el Pliego Único de Bases y Condiciones Generales, por los Pliegos de Bases y Condiciones Particulares según el tipo de demanda y por el de Especificaciones Técnicas Básicas cuando el tipo de demanda fuere reiterativo. Las propuestas serán presentadas cumplimentando determinados requisitos. En el lugar, día y hora fijados para realizar el acto de apertura, el Escribano General de Gobierno abre y examina las propuestas, labrándose un acta de apertura. Para el examen de las propuestas presentadas se confecciona un cuadro comparativo de precios y condiciones. Cada repartición deberá contar con una Comisión Asesora de Pre-adjudicación. La pre-adjudicación recaerá siempre en la propuesta de menor valor. Por excepción, podrá pre-adjudicarse por calidad. Antes de resolver la adjudicación, el organismo deberá acreditar la adecuación del precio ofertado con los vigentes en el sistema de precios referenciales de la Contaduría General de la Provincia. Los oferentes tienen un plazo de tres días hábiles a partir de la notificación de la pre-adjudicación para formular observaciones. Producido el vencimiento del plazo 30 días de mantenimiento de la oferta, el mismo quedará automáticamente prorrogado por el término de 15 días, salvo manifestación expresa del oferente realizada antes del vencimiento. La aprobación de la adjudicación se realiza por acto administrativo. Resuelta la adjudicación, la orden de compra debe emitirse dentro del marco de programación presupuestaria dentro de los 90 días del dictado del acto administrativo. El contrato queda perfeccionado únicamente, mediante la recepción de la orden de compra por parte del adjudicatario quién luego entregará el bien o servicio ajustándose a la forma, fecha, plazos, lugar y demás especificaciones establecidas en el contrato. Las facturas deben ser presentadas por el proveedor en la repartición contratante, las cuales serán conformadas por el jefe de la repartición contratante y abonadas mediante acreditación del dinero en cuenta bancaria dentro de los 30 días de su presentación.

La orden de compra debe estar conformada por el Contador Delegado de cada repartición, quien depende de la Contaduría General de la Provincia de Buenos Aires. Una vez que se 
confecciona la orden de pago, se registra y es firmada por las autoridades de la empresa, el Contador Delegado debe aprobar la orden de pago en forma previa a su pago.

En los que respecta a la registración presupuestaria de las adquisiciones del ARS, actualmente se han fijado exiguos cupos mensuales por parte del Ministerio de Economía de la Provincia de Buenos Aires. Estas restricciones para la ejecución del presupuesto de erogaciones, provocan demoras en la imputación y consecuentemente en el trámite administrativo y en el pago a los proveedores del ARS. Las etapas de la ejecución del gasto con las que debe cumplir el ARS son: el preventivo, el compromiso, el devengado y el pago. El preventivo, es una reserva de crédito que registra las tramitaciones previas a la formalización de los compromisos. No implica ninguna relación jurídica con terceros y se utiliza a los efectos de administrar adecuadamente las aprobaciones de gastos en su etapa inicial. El compromiso, representa la aprobación de la aplicación de recursos por un concepto e importe determinado. Implica el nacimiento de una relación jurídica con terceros, que dará lugar a una eventual salida de fondos. El devengado, implica el surgimiento de una obligación de pago por la recepción de conformidad de bienes o servicios oportunamente contratados. Se produce una modificación cualitativa y cuantitativa en la composición del patrimonio de la repartición, originada por transacciones con incidencia económica y financiera. En esta etapa, se produce la afectación definitiva de los créditos presupuestarios correspondientes. El pago, representa la extinción de la obligación creada en la etapa de devengado.

En cuanto a la ejecución de los recursos, las etapas son: devengado y percibido. El devengado, es el momento en el que por medio de una relación jurídica se establece un derecho de cobro en favor de la repartición y una obligación de pago por parte de las personas físicas o jurídicas obligadas, de naturaleza pública o privada. El percibido, corresponde al momento en el que se produce el ingreso efectivo de fondos.

El ARS también lleva una contabilidad general. A los efectos de la misma, y en cuanto al gasto sólo interesan las etapas de devengado y el pago y en cuanto a los recursos, las etapas de devengado y percibido.

En lo que respecta al manejo de fondos, el ARS se encuentra bajo la órbita del sistema de Cuenta Única del Tesoro (CUT). Este sistema, está basado en el mantenimiento de una única cuenta corriente bancaria en el Banco de la Provincia de Buenos Aires, operada exclusivamente por la Tesorería General de la Provincia de Buenos Aires, hacia la que deben dirigirse todos los recursos recaudados, sean los destinados al Tesoro, propios de jurisdicciones u organismos o vinculados a algún fondo o programa específico, así como los de créditos externos o fondos de terceros. La operatoria del sistema de CUT se divide en cuatro módulos básicos: Ingresos, Programación Financiera, Pagos y el de Conciliación. Estos módulos abarcan cada uno de los aspectos globales del funcionamiento de la Tesorería General bajo el modelo de gestión CUT, para cuya ejecución se desarrolla un sistema de Cuentas Escriturales que identifican la porción de fondos que les corresponden a cada jurisdicción de la administración central y cada organismo descentralizado del total residente en la CUT. Estas Cuentas Escriturales son sub-cuentas registrales de la CUT y se actualizan al registrarse transacciones en el sistema, con lo cual, la sumatoria de los saldos de dichas Cuentas Escriturales conciliará con el saldo de la Cuenta Única del Tesoro. Corresponde a la 
Tesorería General gestionar el proceso de Apropiación de Ingresos de recursos a la CUT como así también el de Conciliación de Pagos.

Incluso el dinero transferido por PDVSA es alcanzado por el sistema de CUT, debiendo el ARS pedir autorización para hacer uso de esos fondos.

Posteriormente, el ARS rinde cuentas ante el Honorable Tribunal de Cuentas de la Provincia de Buenos Aires remitiendo la documentación que éste requiera. El Tribunal puede aplicar llamados de atención, amonestaciones, cargos pecuniarios o multas.

Es necesario distinguir los problemas de organización interna de la empresa como ser los problemas de agencia dentro del ARS, la falta de incentivos, etc. de los problemas de organización institucional que se derivan de la falta de independencia en las decisiones, del excesivo control del gobierno provincial, etc.

El ARS dispone de poca autonomía dado el elevado grado de control que ejerce sobre él el gobierno provincial. Hay que tener en cuenta que se trata de una empresa de producción, en la cual el flujo de materiales que se deben adquirir es mucho mayor con respecto a otro tipo de organismos estatales. El tiempo y los controles que conlleva el proceso de contrataciones, de registración y pago, genera inevitablemente que los proveedores sean cautos, prevean el retraso y coticen a precios superiores. Este retraso en la adquisición de los materiales y servicios necesarios para el ARS, redunda en atrasos en los trabajos de construcciones y reparaciones, lo cual, queda en evidencia ante los clientes, a pesar de las condiciones técnicas y capacidades de construcción de las que dispone el ARS. Esto también provoca que los empleados afectados directamente al área productiva no puedan llevar a cabo su labor al no contar con los insumos necesarios en tiempo y forma. Como se verá en la próxima sección, estas condiciones del ARS inciden en su desempeño presupuestario.

\subsection{Análisis presupuestario del ARS}

El referido análisis se efectuó en base a los datos obtenidos de la Contaduría General de la Provincia de Buenos Aires, en lo referente a la Cuenta Ahorro Inversión Financiamiento del Astillero Río Santiago para los ejercicios 2006 a 2014, ya que los resultados que surgen de la misma (resultado económico, resultado primario, resultado financiero) permiten disponer de indicadores resumen de la política fiscal. El más relevante de esos indicadores es el resultado financiero, o sea, el superávit o déficit fiscal o público, también designado éste último necesidad de financiamiento.

A los valores que arroja la cuenta AIF, se les aplicó un deflactor del PBI, cuya base es del año 2004. De esta forma, los gráficos que se exponen a continuación, se encuentran expresados en pesos constantes del año 2004.

Como se puede apreciar en la Figura 1, los ingresos corrientes del ARS están conformados por: ingresos no tributarios de origen provincial (pasivos perimidos), ingresos de operación (venta bruta de bienes: producido astillero) y en su mayoría, por transferencias corrientes (de gobiernos extranjeros: PDV Marina4, cliente del ARS).

4 Actualmente, existe un contrato con la empresa petrolera venezolana PDVSA para la construcción de buques producteros de 47000 toneladas. En su mayoría, las transferencias corrientes provienen de la referida empresa venezolana. 
Figura 1. Ingresos Corrientes del ARS. En millones de pesos reales. Años 2006-2014.

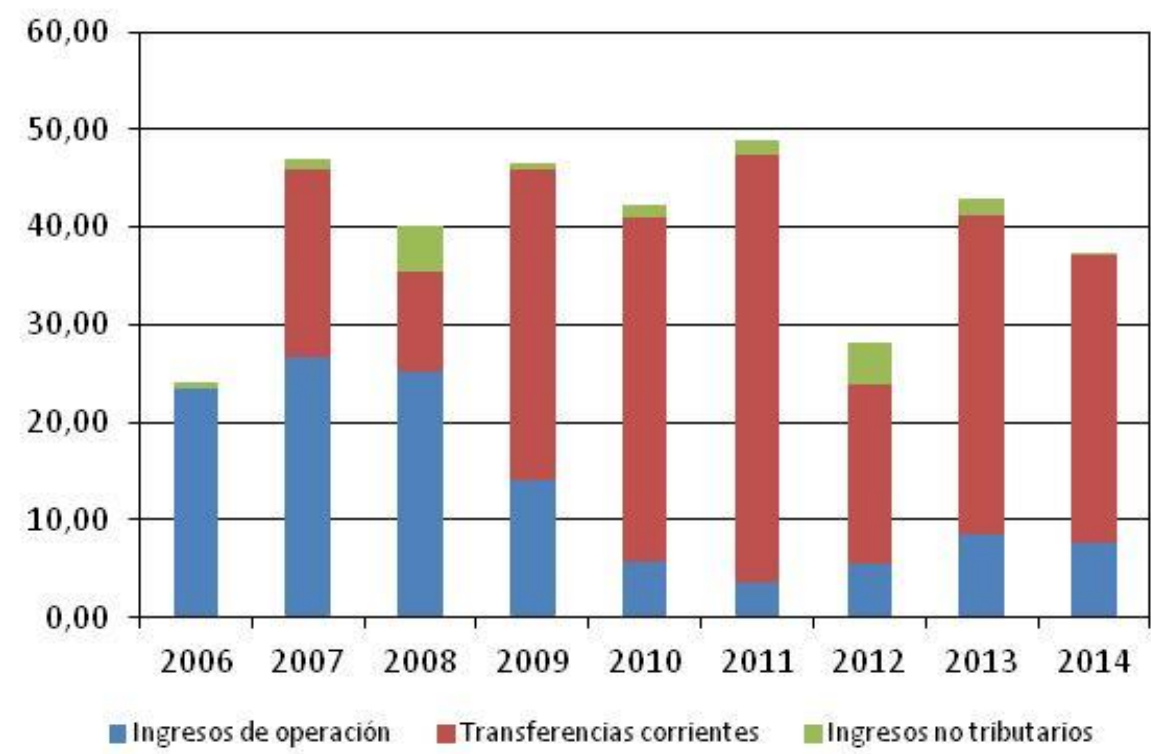

Fuente. Contaduría General de la Provincia de Buenos Aires.

Los gastos corrientes, están formados por gastos de consumo, según puede visualizarse en la Figura 2. Estos últimos, están integrados por: remuneraciones, bienes y servicios e impuestos.

Figura 2. Gastos Corrientes del ARS. En millones de pesos reales. Años 2006-2014.

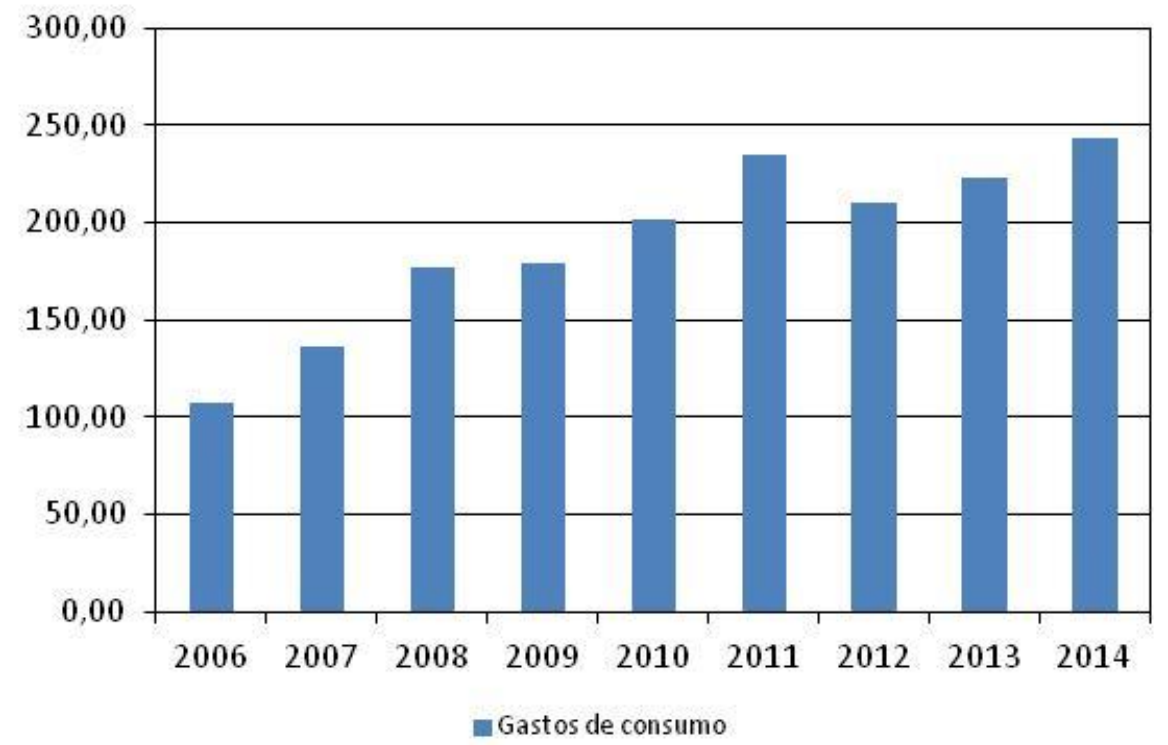

Fuente. Contaduría General de la Provincia de Buenos Aires.

De acuerdo a lo que exhibe la Figura 3, del total de gastos, los mayores son los gastos corrientes y dentro de estos, la mayoría proviene del gasto en sueldos. 
Figura 3. Gastos Totales del ARS. En millones de pesos reales. Años 2006-2014.

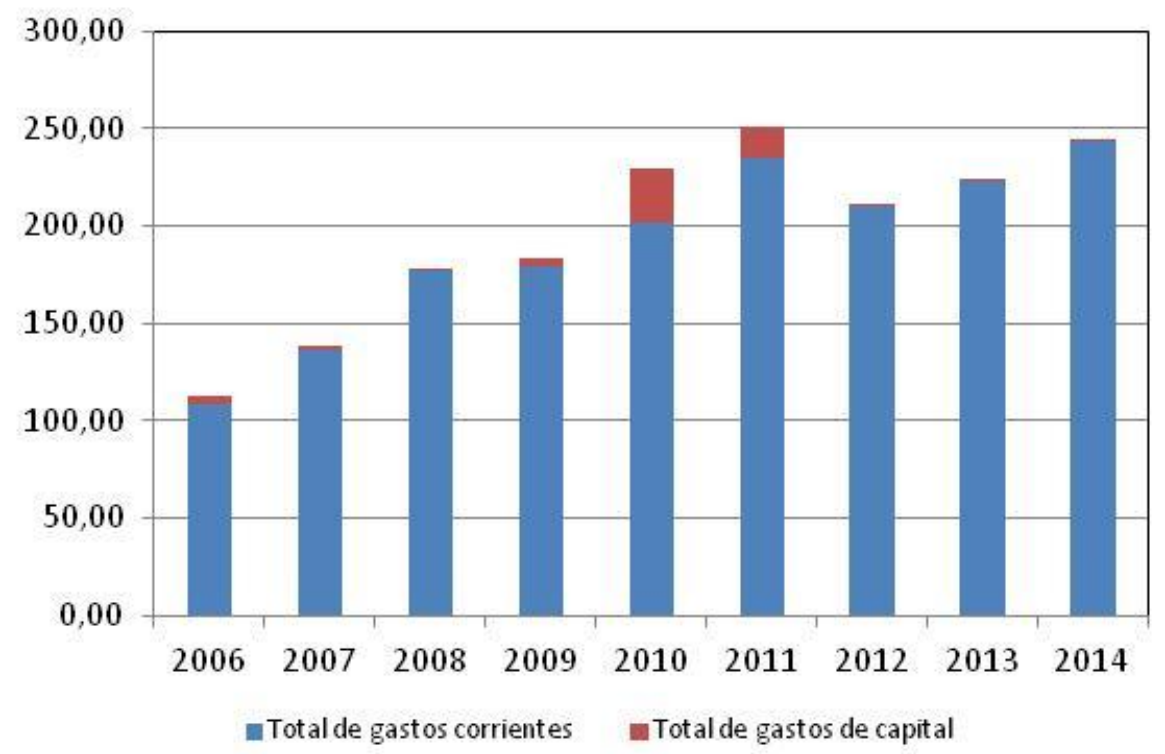

Fuente. Contaduría General de la Provincia de Buenos Aires.

Así, el resultado económico es negativo, implicando un desahorro (déficit), y con una tendencia creciente a lo largo de los últimos años como se puede observar en la Figura 4.

Figura 4. Ingresos Corrientes, gastos corrientes y resultado económico del ARS. En millones de pesos reales. Años 2006-2014.

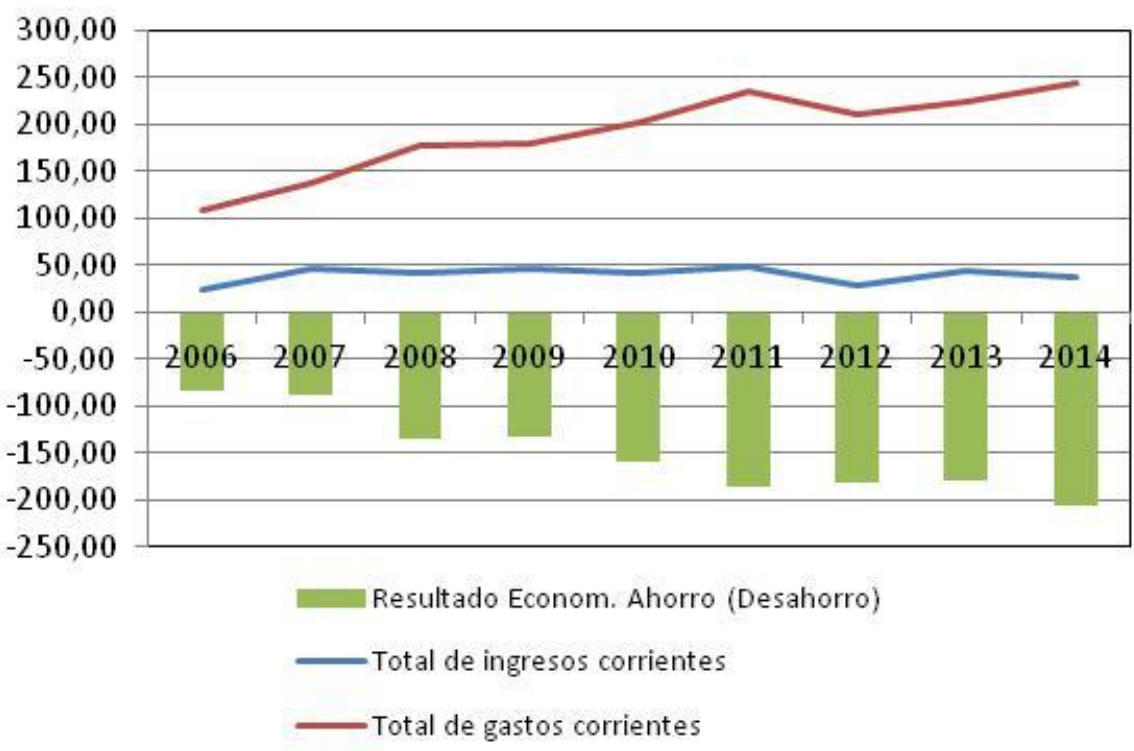

Fuente. Contaduría General de la Provincia de Buenos Aires.

Considerando los ingresos y egresos totales y teniendo en cuenta que los ingresos y gastos de capital son prácticamente nulos, se obtiene que el resultado financiero también es negativo, tal como se muestra en la Figura 5. 
Figura 5. Ingresos totales, Gastos totales y Resultado Financiero del ARS. En millones de pesos reales. Años 2006-2014.

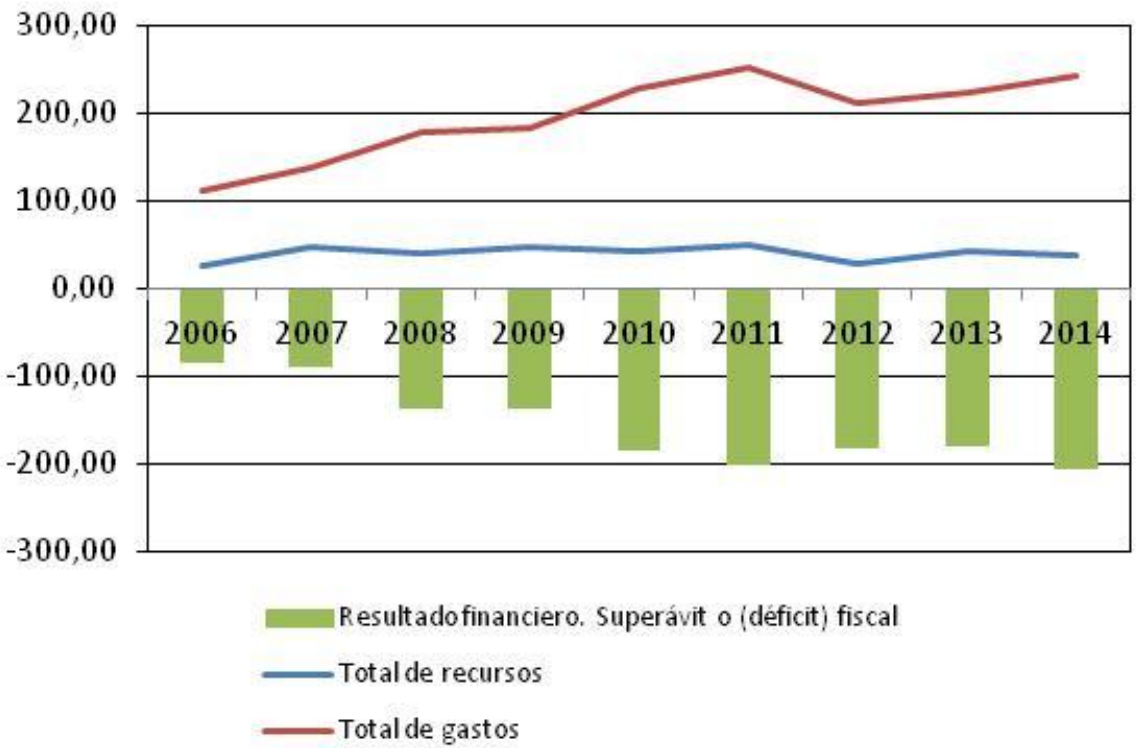

Fuente. Contaduría General de la Provincia de Buenos Aires.

El resultado económico negativo, se cubre con Contribuciones Figurativas para Financiamientos Corrientes, que son las remesas del tesoro provincial destinadas al pago de sueldos. Luego de dichas Contribuciones Figurativas, la configuración de los ingresos cambia, tal como se puede observar en la Figura 6.

Figura 6. Ingresos corrientes con CFFC del ARS. En millones de pesos reales. Años 2006-2014.

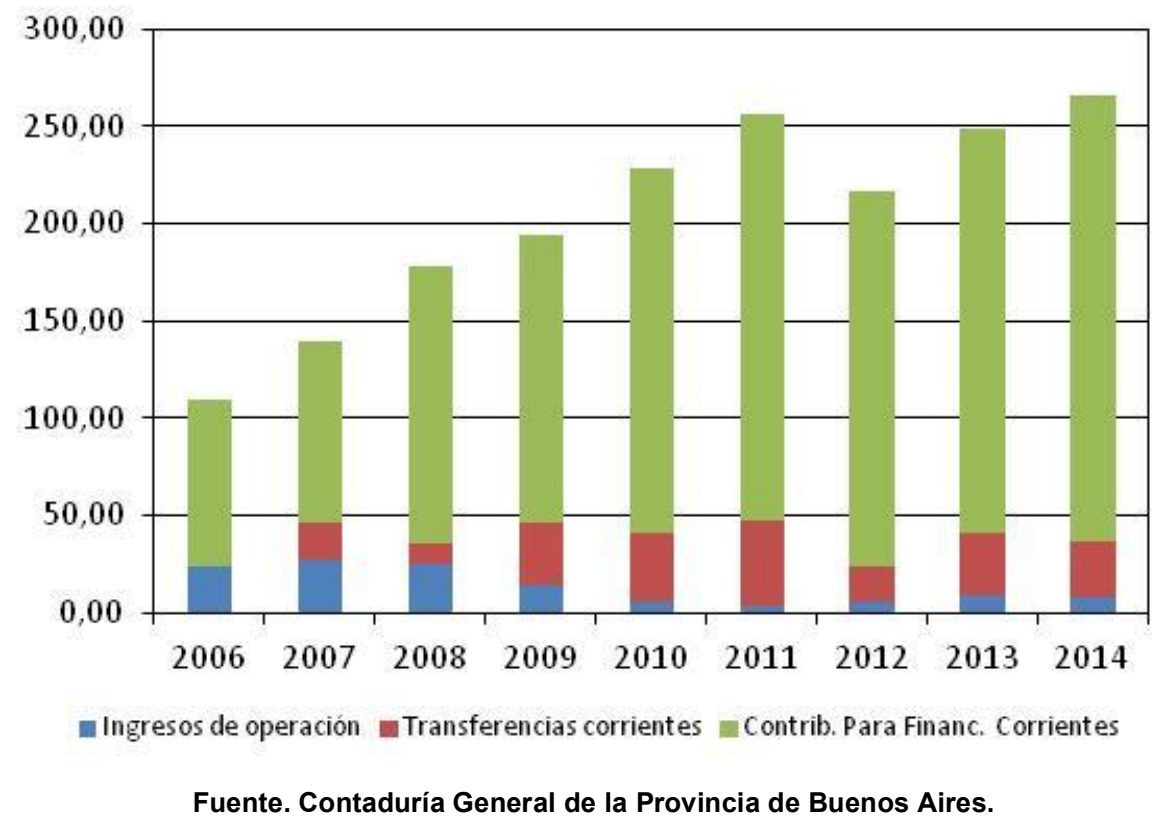

En la Figura 7 que se exhibe a continuación se expone el resultado financiero como porcentaje del gasto total del ARS para cada uno de los períodos analizados. 
Figura 7.Resultado Financiero como porcentaje del Gasto Total del ARS. Años 2006-2014.

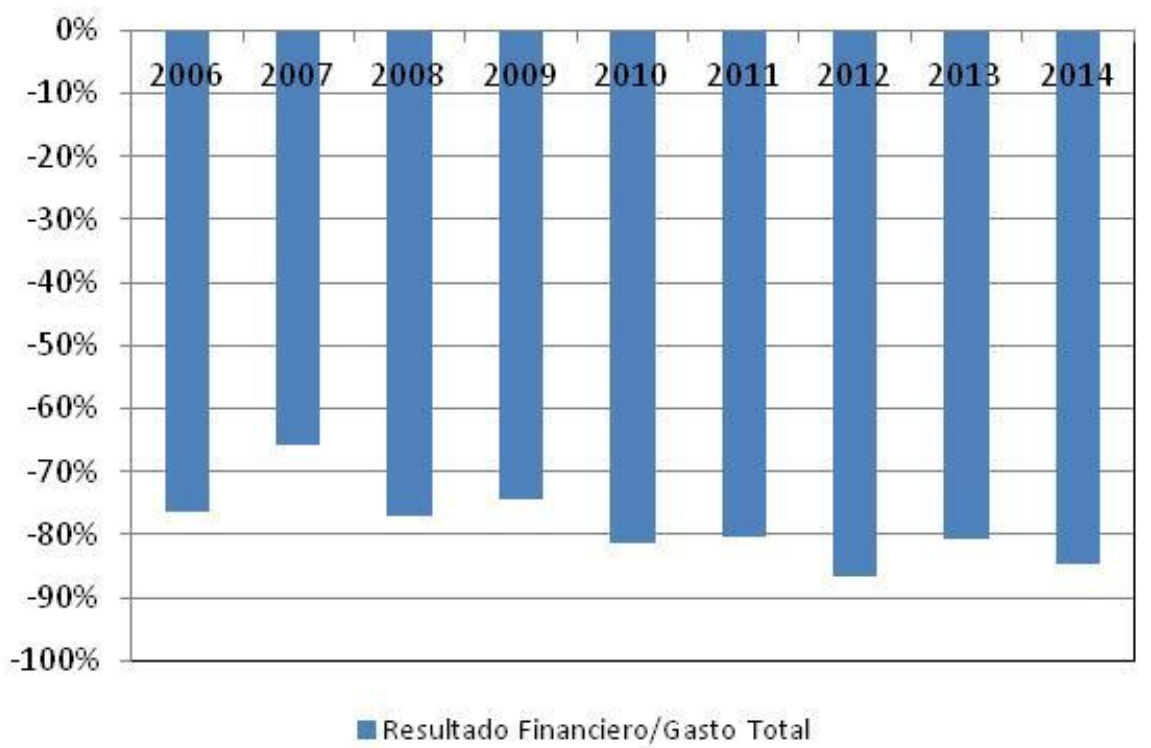

Fuente. Contaduría General de la Provincia de Buenos Aires.

La necesidad de financiamiento arroja un saldo positivo, debido a las contribuciones Figurativas, tal como se observa en la Figura 8.

Figura 8. Contribuciones Figurativas y Necesidad de Financiamiento. En millones de pesos reales. Años 2006-2014.

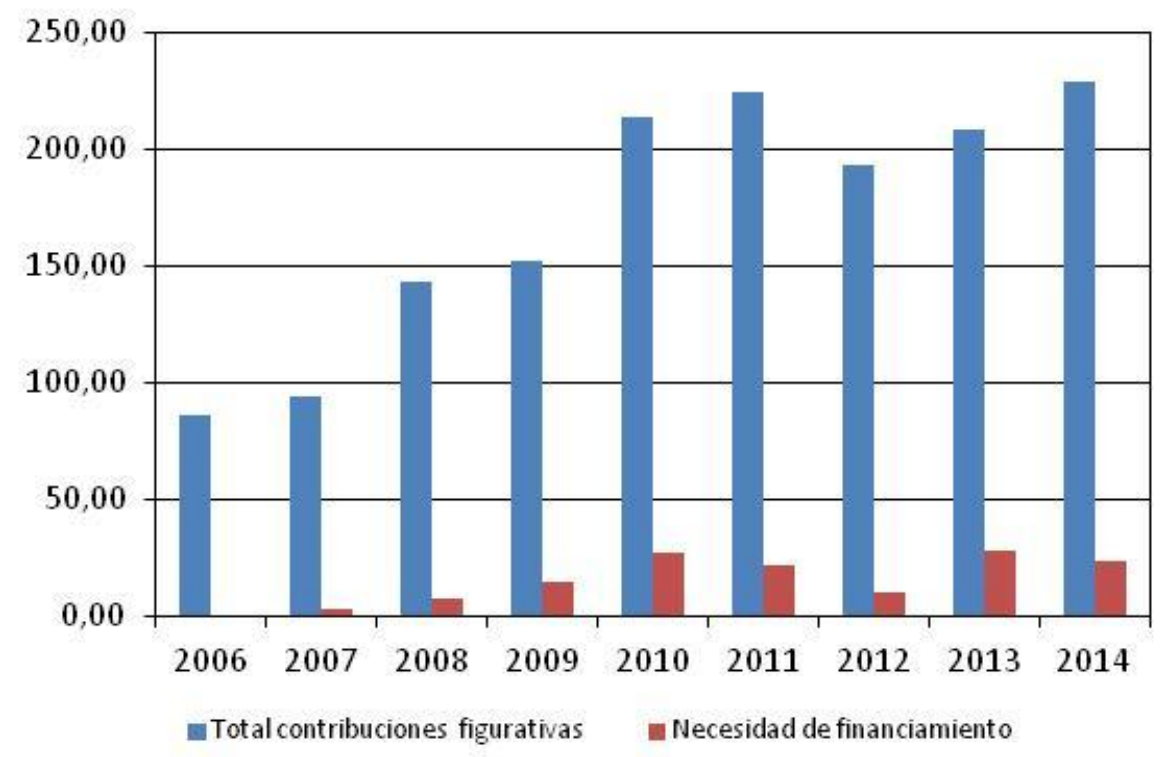

Fuente. Contaduría General de la Provincia de Buenos Aires.

Del análisis de la Cuenta AIF del ARS, se observa que el resultado económico y el financiero son negativos. La mayor parte de sus ingresos provienen de rentas generales y el mayor gasto es en personal. El Ente se financia casi en su totalidad con transferencias del gobierno provincial y poco con sus recursos generados. 
A la luz del enfoque de transparencia fiscal, el ARS opera en una situación deficitaria cubierta por transferencias del gobierno provincial.

Desde el punto de vista de la teoría de empresa pública versus privada y de la teoría del principal agente, este comportamiento observado plantea interrogantes sobre los incentivos de las gerencias y de los encargados de la gestión.

\section{Comparación del funcionamiento presupuestario del ARS}

Hasta el momento el caso del ARS es un caso aislado por lo que resulta interesante verificar si la dinámica observada es común en este tipo de empresas públicas en la industria o si por el contrario, existen manejos diferentes. Para ello, se proponen dos análisis comparativos: uno, a nivel nacional, con Talleres Navales Dársena Norte S.A. Comercial, Industrial y Naviera (Tandanor S.A.C.I. y N.) y otro internacional, con el astillero peruano Servicios Industriales de la Marina S.A. (Sima Perú S.A.).

\subsection{Comparación I: Análisis presupuestario de Tandanor ${ }^{5}$}

El presente análisis se realizó teniendo en cuenta los datos arrojados por la Contaduría General de la Nación, en lo referente a la Cuenta Ahorro Inversión Financiamiento de Tandanor para los ejercicios 2008 a 2012. Lamentablemente para los años 2011, 2013 y 2014, Tandanor no dio cumplimiento a la remisión de información dispuesta por las normas de cierre. Al igual que en el caso del ARS, a los valores que arroja la cuenta AIF, se les aplicó un deflactor del PBI, cuya base es del año 2004. De esta forma, los gráficos que se exponen a continuación, se encuentran expresados en pesos constantes del año 2004.

Como se aprecia en la Figura 9, los ingresos corrientes de Tandanor están dados solamente por sus ingresos de operación, los cuales representan más del doble de los ingresos corrientes del ARS.

5 La descripción general de Tandanor se presenta en el anexo a este trabajo. 
Figura 9. Ingresos Corrientes de Tandanor. En millones de pesos reales. Años 2008, 2009, 2010 y 2012

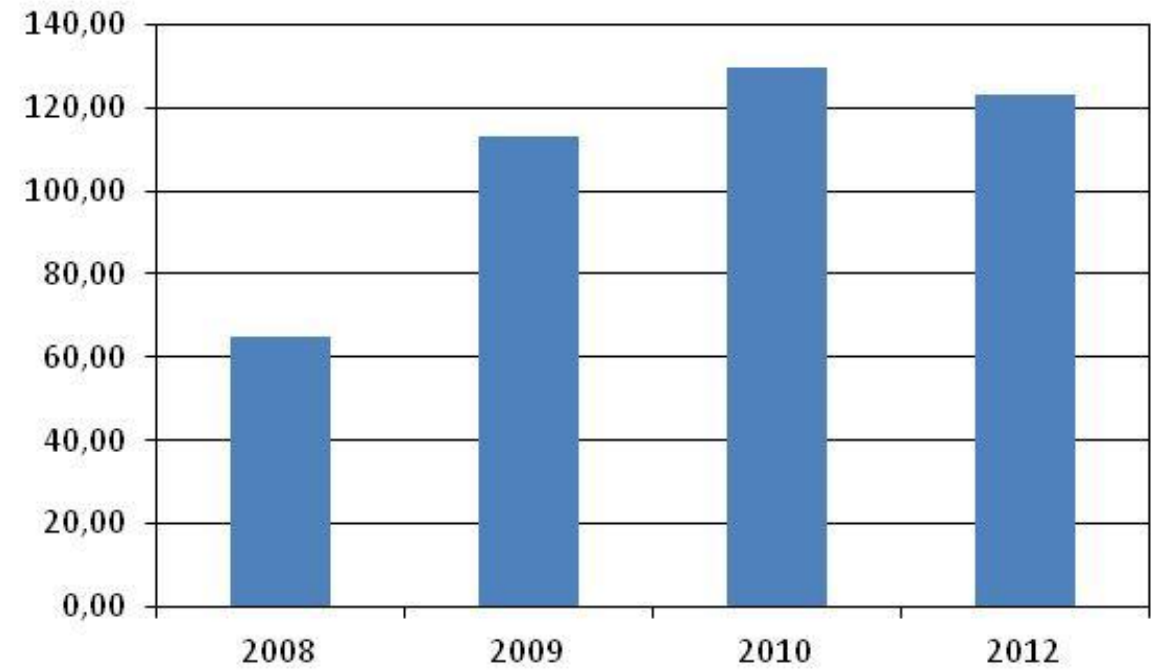

Ingresos de operación - Transferencias corrientes Ingresos no tributarios

Fuente. Contaduría General de la Nación.

Los gastos corrientes de Tandanor, se componen únicamente de los gastos de consumo y dentro de estos, en su mayoría se trata de gastos en bienes y servicios (Figura 10).

Así se puede apreciar que las erogaciones que realiza Tandanor son menores a las que realiza ARS.

Figura 10. Gastos Corrientes de Tandanor. En millones de pesos reales. Años 2008, 2009, 2010 y 2012.

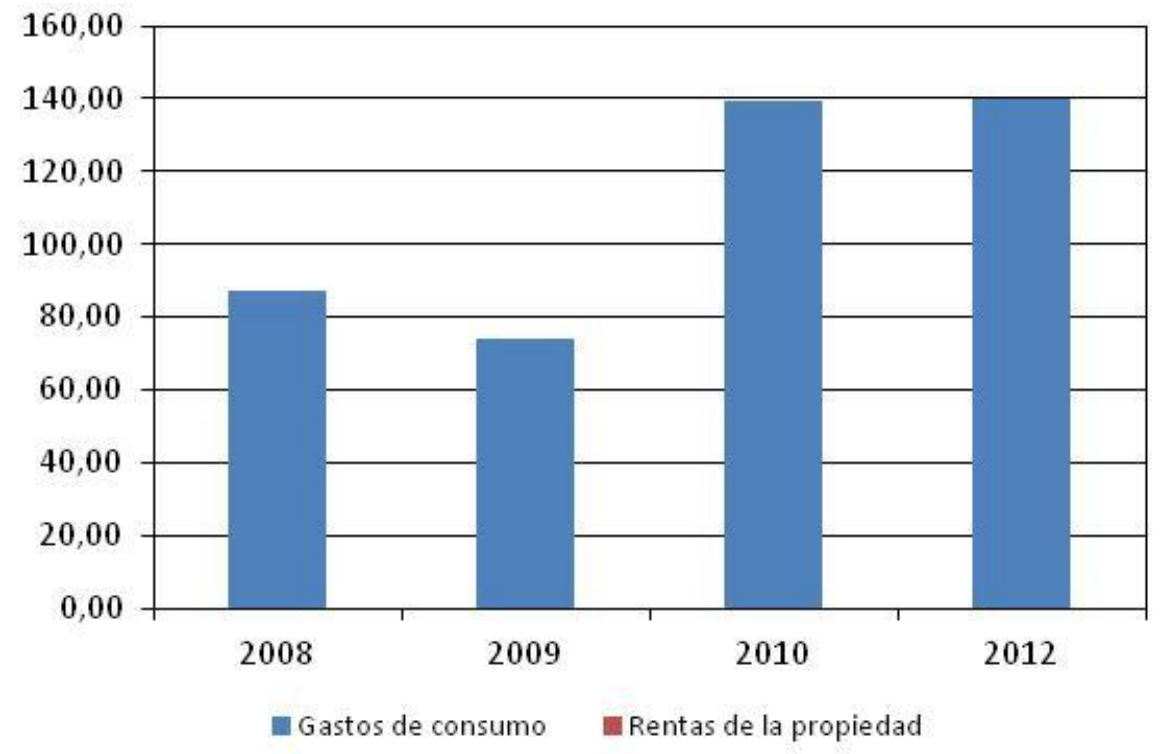

Fuente. Contaduría General de la Nación. 
De acuerdo a lo que se observa en la Figura 11, el resultado económico arroja un déficit modesto, ya que sus ingresos corrientes son mayores y se gasta mucho menos que en el ARS. La tendencia es distinta, ya que muestra períodos de déficit y períodos de superávit.

Figura 11. Ingresos Corrientes, Gastos Corrientes y Resultado Económico de Tandanor. En millones de pesos reales. Años 2008, 2009, 2010 y 2012.

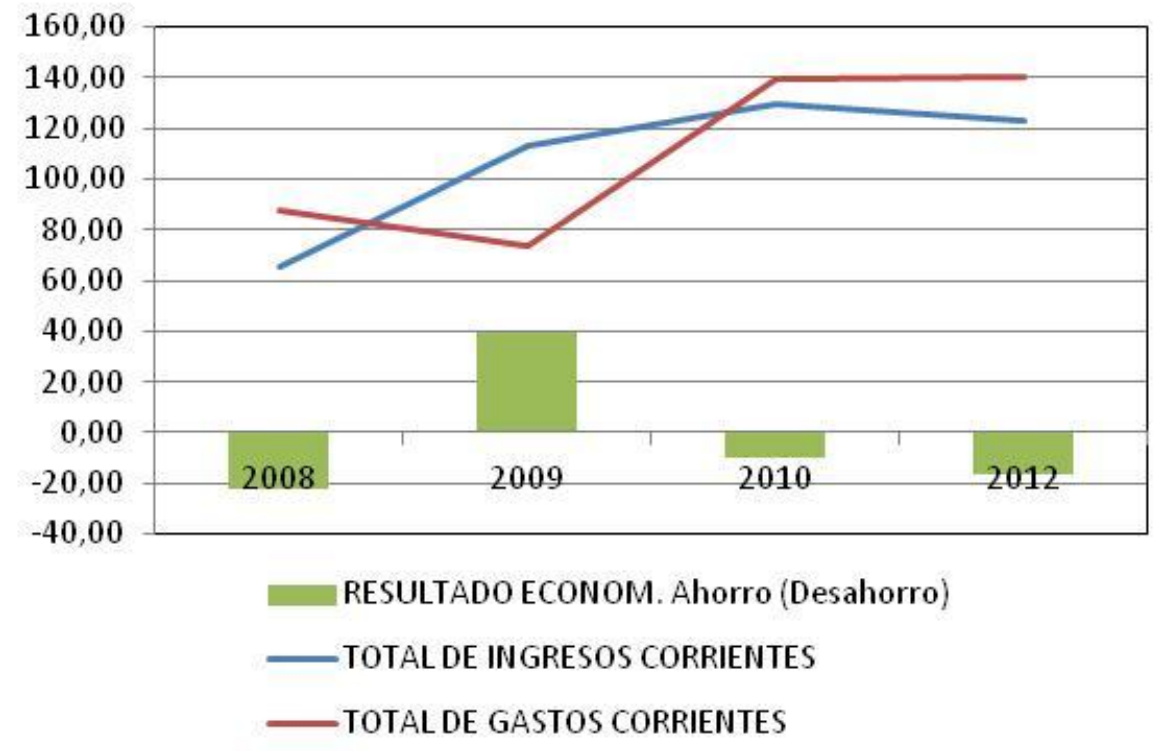

Fuente. Contaduría General de la Nación.

Tal como se observa en la Figura 12, el resultado financiero sigue la misma dinámica que el resultado económico de Tandanor. Los ingresos y gastos de capital son practicamente nulos.

Figura 12. Ingresos Totales, Gastos Totales y Resultado Financiero de Tandanor. En millones de pesos reales. Años 2008, 2009, 2010 y 2012.

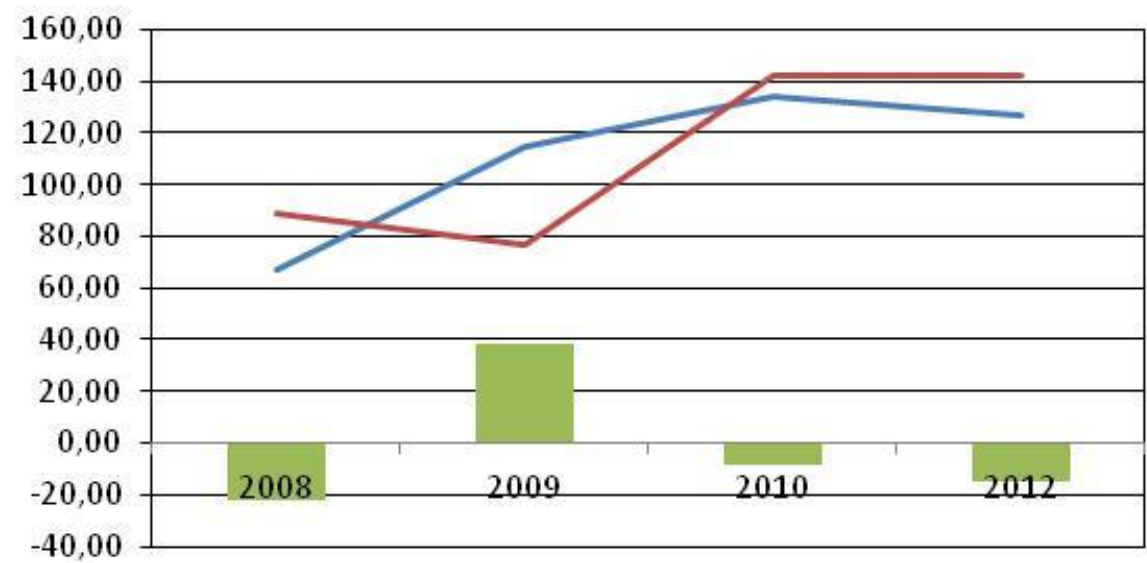

RESULTADO FINANCIERO, Superávit o (déficit) fiscal

—TOTAL DE RECURSOS

TOTAL DE GASTOS

Fuente. Contaduría General de la Nación. 
En la Figura 13, se muestra el resultado financiero como porcentaje del gasto total de Tandanor para cada uno de los períodos analizados. Se observa que el resultado económico y el financiero son negativos, excepto en el ejercicio 2009.

Figura 13. Resultado Financiero como porcentaje del Gasto Total de Tandanor. Años 2008, 2009, 2010 y 2012.

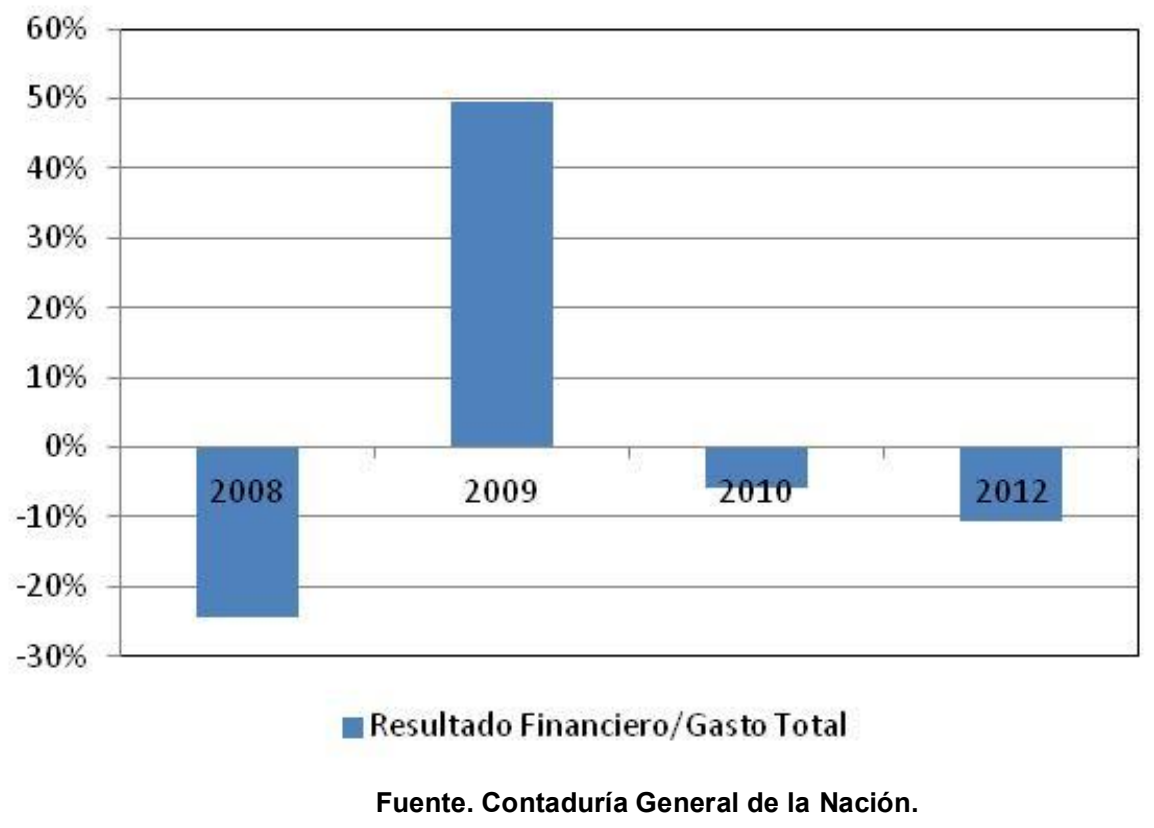

\subsection{Comparación II: Análisis presupuestario de Sima (Perú) $)^{6}$}

El presente análisis se realizó teniendo en cuenta los Presupuestos de Ingresos y Egresos de Sima arrojados por el FONAFE, para los ejercicios 2007 a 2014. En base a ellos, se confeccionó la cuenta AIF de SIMA a los efectos de poder compararla con la de los dos astilleros argentinos estudiados. Los valores se encuentran expresados en nuevos soles peruanos ${ }^{7}$ a los cuales se les aplicó un deflactor, cuya base es del año 2007. De esta forma, los gráficos que se exponen a continuación, se encuentran expresados en nuevos soles peruanos constantes del año 2007.

De acuerdo a lo que se observa en la Figura 14, en cuanto a los ingresos corrientes de Sima - Perú, en su mayoría se trata de ingresos de operación.

6 La descripción general de Sima se presenta en el anexo a este trabajo.

7 La paridad cambiaria es de 100 ARS $=35$ SOLES. 
Figura 14. Ingresos Corrientes de Sima - Perú. En millones de nuevos soles reales. Años 2007-2014.

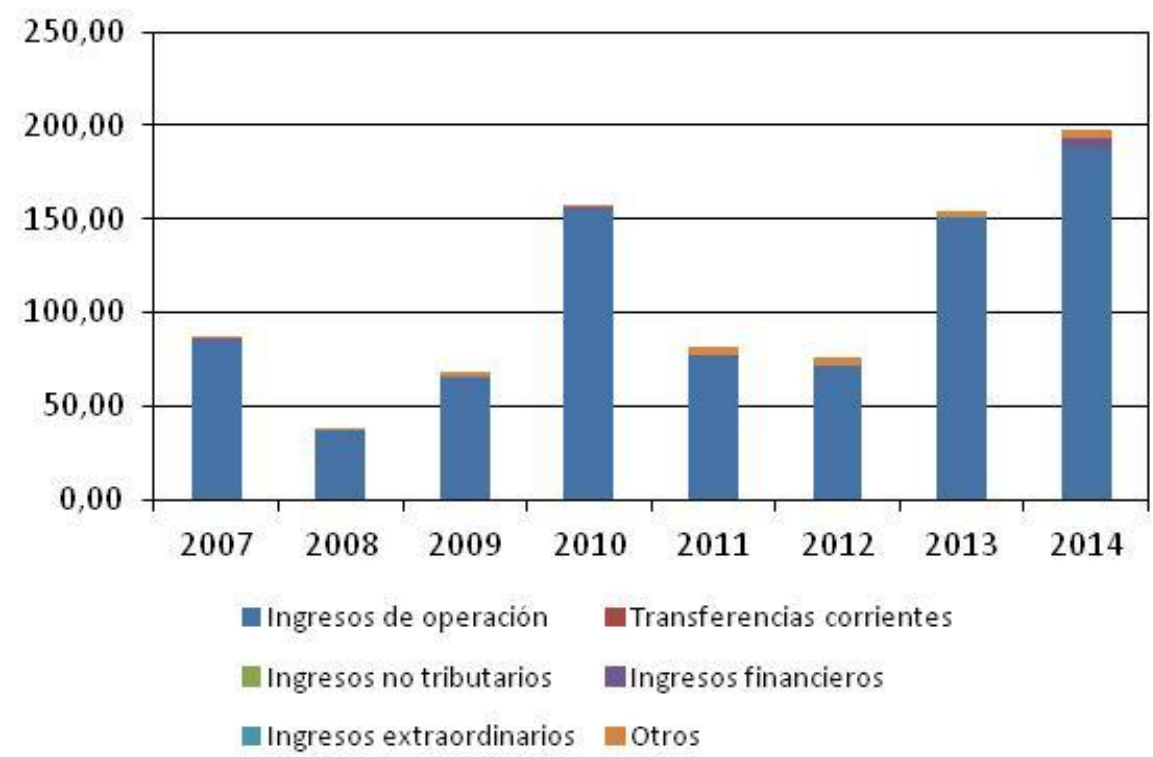

Fuente: Fondo Nacional de Financiamiento de la Actividad Empresarial del Estado (Perú)

Los gastos corrientes se componen en su mayoría de gastos en bienes y servicios (Figura 15).

Figura 15. Gastos Corrientes de Sima - Perú. En millones de nuevos soles reales. Años 2007-2014.

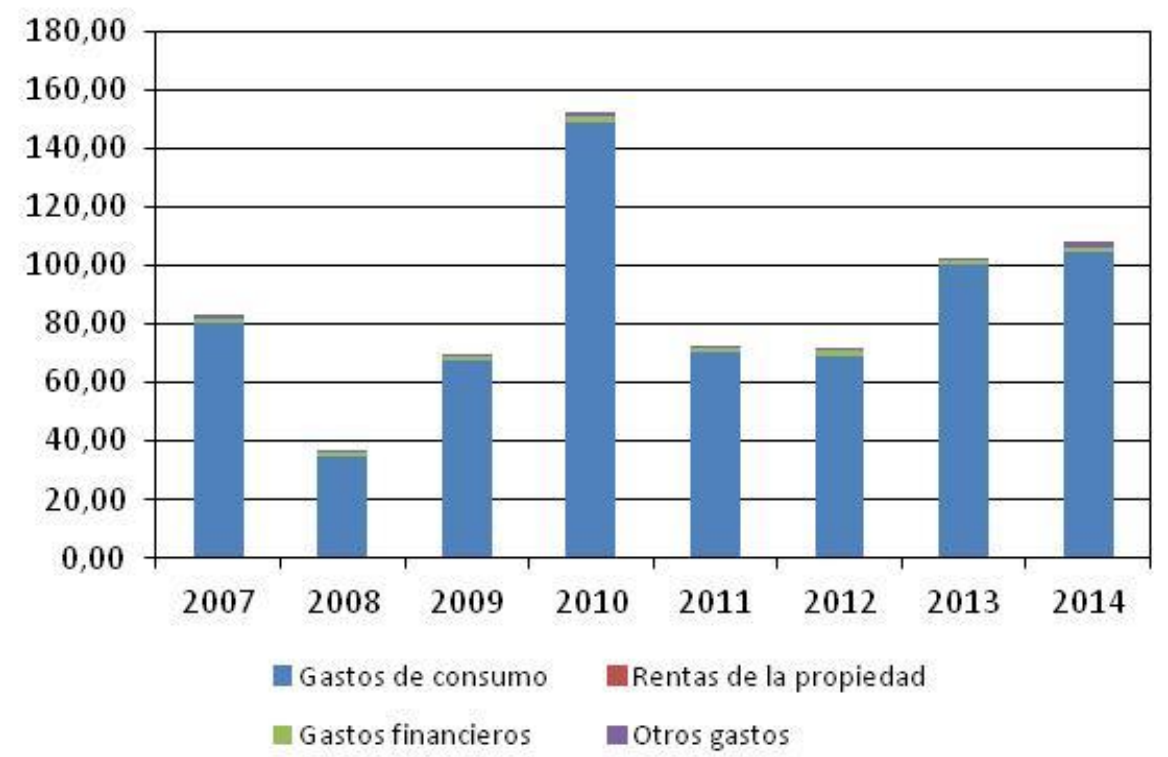

Fuente: Fondo Nacional de Financiamiento de la Actividad Empresarial del Estado (Perú)

En cuanto al resultado económico de Sima - Perú, el mismo, arroja superávit en casi todos los períodos analizados, tal como se observa en la Figura 16. 
Figura 16. Ingresos Corrientes, Gastos Corrientes y Resultado Económico de Sima - Perú. En millones de nuevos soles reales. Años 2007-2014.

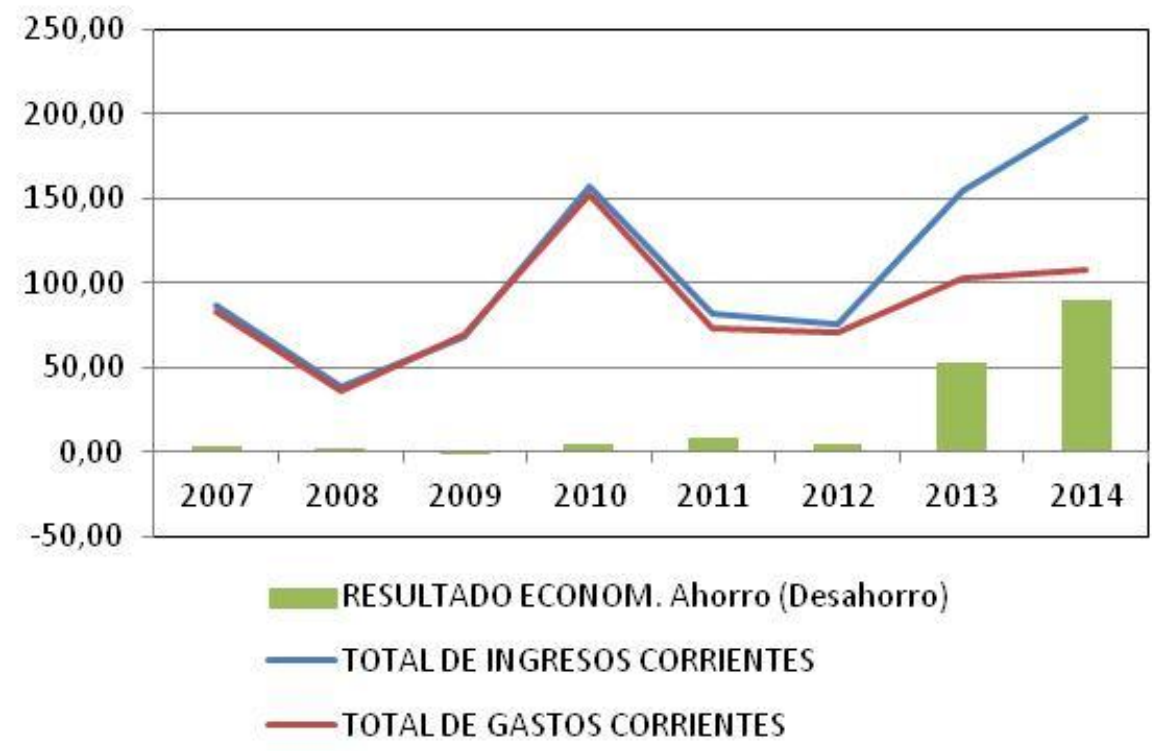

Fuente: Fondo Nacional de Financiamiento de la Actividad Empresarial del Estado (Perú)

En lo que respecta al resultado financiero de Sima - Perú, en la Figura 17 se evidencia que es mayor la incidencia de los ingresos y gastos de capital en este astillero en comparación con el ARS y Tandanor.

Figura 17. Ingresos Totales, Gastos Totales y Resultado Financiero de Sima - Perú. En millones de nuevos soles reales. Años 2007-2014.

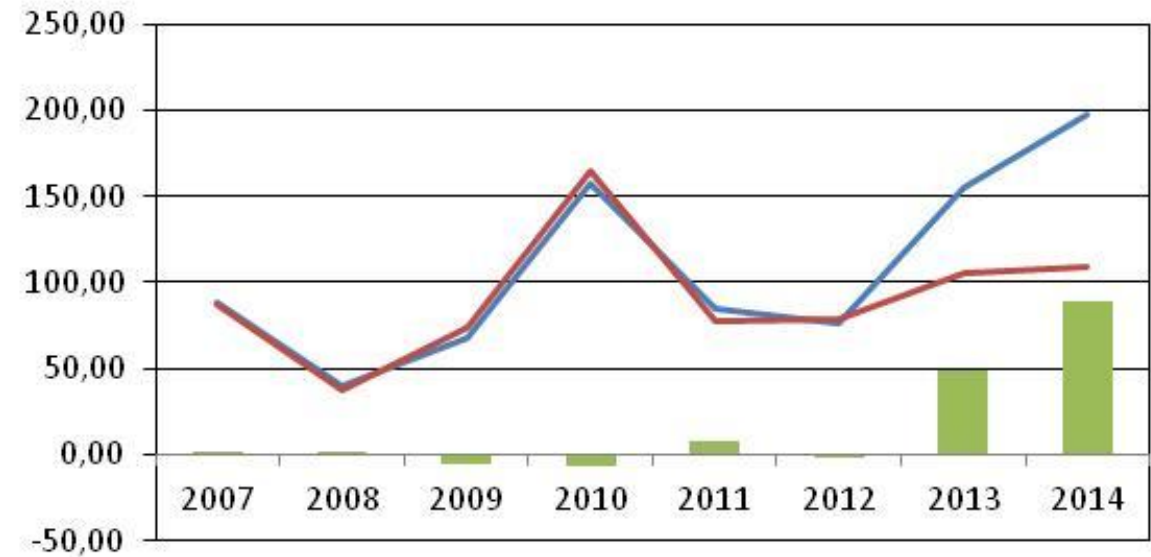

RESULTADO FINANCIERO. Superávit o (déficit) fiscal

-TOTAL DE RECURSOS

TOTAL DE GASTOS

Fuente: Fondo Nacional de Financiamiento de la Actividad Empresarial del Estado (Perú)

A continuación, en la Figura 18 se expone el resultado financiero como porcentaje del gasto total de Sima - Perú para cada uno de los períodos analizados. 
Figura 18. Resultado Financiero como porcentaje del gasto total de Sima - Perú. Años 2007-2014.

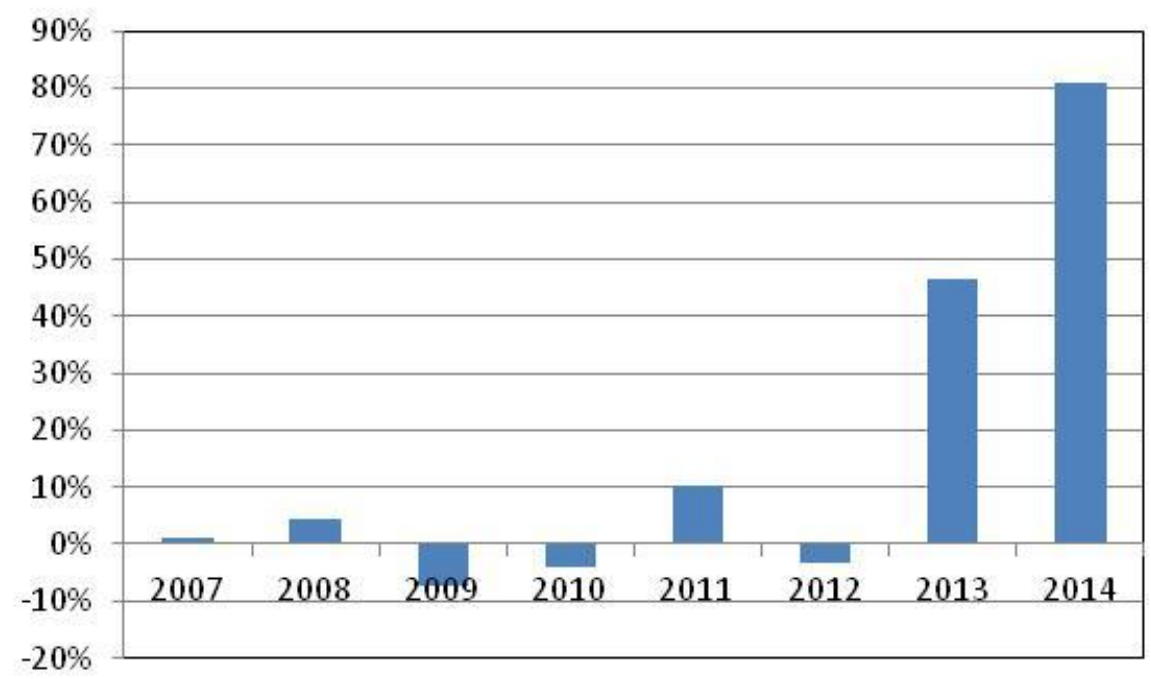

Resultado Financiero/Gasto Total

Fuente: Fondo Nacional de Financiamiento de la Actividad Empresarial del Estado (Perú)

Del análisis presupuestario del ARS, se observa que el principal gasto corriente es el gasto en sueldos, a diferencia de Tandanor y Sima, donde el mayor gasto corriente es en bienes y servicios. EI ARS cuenta con una nómina de 2.295 cargos de personal. Presenta un núcleo sindical muy importante y en lo referente a la capacitación, posee una escuela técnica privada de fábrica reconocida por la Dirección General de Cultura y Educación de la Provincia de Buenos Aires tendiente a la formación de recursos humanos para la industria naval.

En cuanto a la incidencia de los ingresos y gastos de capital, es mayor en el caso de Sima en comparación con el ARS y Tandanor, en los cuales, los ingresos y gastos de capital son prácticamente nulos.

Habiendo analizado la Cuenta AIF del ARS, se observa que el resultado económico y el financiero son negativos. El Ente se financia casi en su totalidad con transferencias del gobierno provincial y poco con sus recursos generados.

En el caso de Tandanor, el resultado económico arroja un déficit modesto, puesto que sus ingresos corrientes son mayores y se gasta mucho menos que en el ARS. La tendencia es distinta, ya que muestra períodos de déficit y períodos de superávit. El resultado financiero sigue la misma dinámica que el económico. Hay que tener en cuenta que la cantidad de empleados de Tandanor es una cuarta parte de la nómina de personal del ARS y que Tandanor está orientado a reparaciones navales y no a construcciones de buques de gran porte como es el caso del ARS.

El resultado económico de Sima arroja superávit en casi todos los períodos analizados. Lo mismo sucede con su resultado financiero. 


\section{Conclusiones}

Los resultados que se deprenden del análisis, son que el ARS opera en una situación deficitaria sostenida, cubierta por transferencias del gobierno provincial.

Quizás ese déficit presupuestario permanente encuentre, en parte, justificación en la reducción de la capacidad instalada del ARS ocasionada cuando el mismo fue transferido al gobierno de la Provincia de Buenos Aires y aprobada la instalación de la Zona Franca de La Plata en el predio que hasta entonces pertenecía al ARS. El nivel de actividad del ARS es mucho menor en relación a su infraestructura si se lo compara cuando el mismo era una Sociedad Anónima del Estado y cuando en la década del 70 y 80 tenía como clientes principales a la Armada Nacional, a la Empresa de Líneas Marítimas Argentinas (ELMA) y a Yacimientos Petrolíferos Fiscales (YPF), habiéndose formado un entramado productivo muy importante. Así se verifica que las empresas estatales de cada país son las generadoras de la principal demanda del sector naval.

Otro de los inconvenientes que se evidencia en el ARS es su falta de autonomía inherente a su organización institucional actual, ya que siendo una empresa de producción debe cumplir con los plazos que conllevan las contrataciones en el ámbito de la administración pública provincial y presenta inconvenientes en cuanto a la registración de las adquisiciones de materiales, bienes de uso y prestaciones de servicios ya que para ello cuenta con exiguos cupos mensuales fijados por parte del Ministerio de Economía de la Provincia de Buenos Aires, todo lo cual redunda en atrasos en la construcción de los buques. Hay que tener en cuenta el elevado nivel de agregación incorporado en los buques, la complejidad del proceso productivo y la utilización de insumos, equipos e instalaciones provenientes de una amplia gama de sectores manufactureros.

Si bien la industria naval es una actividad fuertemente subvencionada en todo el mundo, en la región existe evidencia de empresas públicas navales, (por ejemplo: Sima Perú S.A. - empresa estatal de derecho privado -) que muestra un comportamiento inverso al del ARS desde el punto de vista presupuestario al menos.

Por otro lado, desde el punto de vista de la teoría de la empresa pública versus privada y de la teoría del principal agente, este comportamiento observado en el ARS (déficit cubierto por transferencias del gobierno provincial) plantea interrogantes sobre los incentivos de las gerencias y de los encargados de la gestión ya que la posibilidad de vincular premios con resultados resulta compleja.

Desde el punto de vista de la administración financiera, el ARS cumple con el principio del acceso del público a la información, demostrando así transparencia fiscal. Como pudo observarse, el ARS presenta información completa sobre su actividad, poniéndola a disposición del público de manera oportuna, publicándola en Internet con acceso fácil y gratuito y rindiendo cuentas ante el Honorable Tribunal de Cuentas de la Provincia de Buenos Aires.

Resulta imprescindible para revertir la tendencia observada en el ARS, dotarlo de autonomía, desburocratizar en lo posible la gestión pública relacionada al sector y fijar un mecanismo de metas e incentivos compatibles con un presupuesto que equilibre gastos y recursos de manera genuina. 


\section{Bibliografía}

- Barbosa Pereira, Luisa y Frassa, Juliana, 2013. "Estado y relaciones laborales en la industria de construcción naval en el Mercosur. Un estudio comparativo de dos estudios de caso". VII Congreso latinoamericano de estudios del trabajo.

- FIEL, 1999. "La regulación de la competencia y de los servicios públicos: teoría y experiencia argentina reciente".

- FINA, 2005. "Cadena de valor de la industria naval en la Región Pampeana". Documento de trabajo, Federación de la Industria Naval Argentina, Buenos Aires.

- Fondo Monetario Internacional, 2007. "Manual de transparencia fiscal".

- Frassa, Juliana y Russo, Cintia, 2012. "Trayectoria reciente y perspectivas futuras de la industria naval pesada argentina: los astilleros estatales". Revista de Estudios Regionales, págs. 77-98.

- Frassa, Juliana, 2007. "El papel de los saberes productivos en las trayectorias empresariales frente a un contexto en transformación". Instituto de Investigaciones en Comunicación.

- Frassa, Juliana, Muñiz Terra, Leticia y Naclerio, Alejandro, 2009. "Trayectorias empresariales divergentes frente a contextos de privatización. Un estudio comparativo de dos empresas públicas argentina."

- Garriga, Marcelo y Rosales Walter, 2013. "Finanzas Públicas en la Práctica. Selección de casos y aplicaciones".

- Gasparini, Leonardo, Arcidiácono, Malena, Carella, Laura, Puig, Jorge, Gluzmann, Pablo y Brassiolo, Pablo, 2015. "El empleo público en América Latina. Evidencia de las encuestas de hogares". El Trimestre Económico, vol. LXXXII (4), núm. 328, octubre-diciembre de 2015, pp. 749-784.

- Mauro, Lucía Mercedes, 2011."La industria naval como un sector estratégico: análisis del rol del Estado en su desarrollo". VI Jornadas de Jóvenes Investigadores. Instituto de Investigaciones Gino Germani.

- Stiglitz, Joseph, 1995. "La economía del sector público",

- Versino, Mariana, Frassa, Juliana, Guedes de Jesus, Claudiana y De Gitahy, Leda, 2010. "La industria naval pesada en Argentina y Brasil: la intervención del estado en sectores estratégicos en el Mercosur". Jornadas Nacionales sobre Estudios Regionales y Mercado del Trabajo. 
ANEXO I. Descripción general de los Astilleros utilizados como base de comparación del ARS

\section{Tandanor}

La historia de este astillero se remonta a más de 130 años, cuando el 18 de noviembre de 1879, el presidente Nicolás Avellaneda puso en funcionamiento los Talleres Navales de Marina para el mantenimiento de los buques de la Armada Nacional.

En 1922 el astillero fue rebautizado Arsenal Naval Buenos Aires.

Cuando la flota mercante estatal fue creada, en 1942, el astillero debió preparar, reparar y poner en servicio los antiguos buques extranjeros comprados para este propósito.

En 1971, debido a la creciente necesidad de la flota mercante estatal, se reformuló Tandanor bajo su denominación actual, y se constituyó como una empresa dirigida por la Armada Argentina y la Administración General de Puertos, bajo el sistema legal de una sociedad anónima, con mayoría de capital estatal.

En 1973, la Armada incorpora el personal y propiedad de Tarena, otro importante astillero estatal. En aquel momento los ocho diques de Tandanor estaban completos y la necesidad de ampliar las facilidades del astillero se hizo presente.

Esta falta de capacidad de reparación, dio lugar a un considerable escozor entre los armadores de buques de bandera argentina quienes estaban forzados a reparar en el exterior, con el consecuente gasto en moneda extranjera y el factor negativo respecto a los tiempos de entrega. Esta situación puso en relieve la necesidad de agrandar las instalaciones. La Armada aprobó el proyecto y en enero de 1978 comenzó la construcción del plan de ampliación.

Se firmó un contrato con Pearlson Ingeniería en Miami (EE.UU.) cuyo director fue el inventor del sistema de elevación de buques Syncrolift. El sistema permitía ampliar la capacidad del astillero ya que sacaba los buques del agua para que fueran trasladados a alguna de las seis gradas de reparación del complejo.

En 1990, durante la presidencia de Carlos Menem, Tandanor fue privatizado, comenzando un proceso de declive y vaciamiento de la gestión privada que culminó con el pedido de quiebra sólo nueve años después.

En 2002, se realiza un concurso de acreedores, mientras que paralelamente se inicia la recuperación del astillero gracias a la resistencia activa de los trabajadores.

En 2007, el presidente Néstor Kirchner decide estatizar las acciones de los Talleres Navales Dársena Norte S.A. Comercial Industrial y Naviera (Tandanor S.A.C.I. y N.) por Decreto ${ }^{\circ} 315 / 07$ declarando nula de nulidad absoluta la privatización realizada en la década anterior. Los trabajadores del astillero recibieron el $10 \%$ de sus acciones. El resto, corresponde al Estado Nacional, funcionando bajo la órbita del Ministerio de Defensa.

El 17 de Mayo del año 2010, Tandanor se unió con el Astillero Almirante Storni creándose el Complejo Industrial Naval Argentino (CINAR), comenzando a funcionar como una sola unidad dedicada a la reparación, conversión y construcción naval, y más recientemente, a la industria metalmecánica.andanor se encuentra ubicado en la zona portuaria de la Ciudad de Buenos Aires. En 
el Canal Sur, sobre el Estuario del Río de La Plata, único acceso a la Hidrovía formada por los ríos Paraguay, Paraná y De La Plata, sobre los cuales se encuentran los puertos aptos para operaciones con buques oceánicos. Al norte, y ya sobre la costa atlántica, se encuentran los principales puertos del Brasil, y al sur, los más importantes puertos marítimos -comerciales y turísticos- de la Patagonia Argentina.

En cuanto a su organigrama, tiene un Directorio formado por un presidente, vicepresidente y dos directores; y seis gerencias.

Las áreas de producción consisten en: construcciones y reparaciones navales, en las 21 hectáreas del predio de CINAR se realizan tareas de reparaciones navales y se construyen navíos y barcazas de diversas categorías. Los talleres de Tandanor y los del Alte. Storni trabajan como una unidad funcional, prestando servicios a navieras y petroleras del mundo. Metalmecánica, a partir del año 2012 se tomó la decisión de de diversificar la producción para brindar soluciones en metalmecánica pesada para las industrias del gas, petróleo, minería y de otras ramas del sector energético.

\section{Sima}

Servicios Industriales de la Marina S.A. (SIMA PERÚ S.A.), se constituyó en 1950 como empresa pública y en 1999 se convirtió en una empresa estatal de derecho privado que opera de acuerdo a la política del Ministerio de Defensa, de la Comandancia General de la Marina y del Fondo Nacional de Financiamiento de la Actividad Empresarial del Estado (FONAFE). Este último, es propietario del $100 \%$ de las acciones de la empresa.

Su objeto es efectuar la reparación, carena, alteración y construcción de buques, establecer y operar astilleros, factorías, talleres, varaderos y prestar los servicios propios de la construcción y reparación naval, y realizar actividades en el campo de metal mecánica y obras complementarias y conexas.

Su misión es efectuar el mantenimiento, modernización y construcción de las Unidades de Marina de Guerra del Perú, y ejecutar proyectos relacionados con la industria naval y metal mecánica para el sector estatal y privado, nacional y extranjero dentro de los más exigentes estándares de calidad, con el fin de contribuir a la defensa y el desarrollo socio-económico y tecnológico del país.

Su visión es ser reconocido como el mejor astillero naval en Latinoamérica. La empresa cuenta con tres centros de operaciones, los cuales se ubican en: Callao, Chimbote e Iquitos (filial de Sima Perú). Sus principales líneas de negocio son: las reparaciones navales (mantenimiento preventivo y correctivo a embarcaciones de alto y bajo bordo o averías en casco); construcciones navales (construcción de embarcaciones de alto y bajo bordo. Puede ofrecer al mercado naviero, no sólo dentro del país, la construcción de naves de cuyo tonelaje sea menor o igual a 25.000 toneladas) y metal mecánica (producción de estructuras metálicas: puentes metálicos, torres, hidromecánicos para centrales hidroeléctricas, estructuras portuarias, tanques, etc.)

En cuanto a su organigrama, Sima cuenta con ocho directores y un presidente de directorio. Emplea a más de 2000 personas entre ingenieros y personal técnico experimentado. 
ANEXO II. Cuenta AIF del ARS en millones de pesos corrientes. Años 2006 a 2014.

\begin{tabular}{|c|c|c|c|c|c|c|c|c|c|}
\hline & 2006 & 2007 & 2008 & 2009 & 2010 & 2011 & 2012 & 2013 & 2014 \\
\hline \multicolumn{10}{|l|}{ CUENTA CORRIENTE } \\
\hline Ingresos corrientes & 30,83 & 70,54 & 73,69 & 93,02 & 99,14 & 135,09 & 91,93 & 168,38 & 188,77 \\
\hline Ingresos tributarios & 0,00 & 0,00 & 0,00 & 0,00 & 0,00 & 0,00 & 0,00 & 0,00 & 0,00 \\
\hline de origen provincial & 0,00 & 0,00 & 0,00 & 0,00 & 0,00 & 0,00 & 0,00 & 0,00 & 0,00 \\
\hline de origen nacional & 0,00 & 0,00 & 0,00 & 0,00 & 0,00 & 0,00 & 0,00 & 0,00 & 0,00 \\
\hline Aportes y contribuciones & 0,00 & 0,00 & 0,00 & 0,00 & 0,00 & 0,00 & 0,00 & 0,00 & 0,00 \\
\hline Ingresos no tributarios & 0,81 & 1,69 & 8,62 & 1,31 & 3,10 & 4,04 & 13,77 & 7,27 & 1,80 \\
\hline de origen provincial & 0,81 & 1,69 & 8,62 & 1,31 & 3,10 & 4,04 & 13,77 & 7,27 & 1,80 \\
\hline de origen nacional & 0,00 & 0,00 & 0,00 & 0,00 & 0,00 & 0,00 & 0,00 & 0,00 & 0,00 \\
\hline Venta de bienes y scios de la Adm Pública & 0,00 & 0,00 & 0,00 & 0,00 & 0,00 & 0,00 & 0,00 & 0,00 & 0,00 \\
\hline Ingresos de operación & 30,02 & 40,05 & 45,87 & 28,00 & 13,23 & 10,01 & 18,05 & 32,92 & 39,00 \\
\hline Rentas de la propiedad & 0,00 & 0,00 & 0,77 & 0,00 & 0,00 & 0,00 & 0,00 & 0,00 & 0,00 \\
\hline Transferencias corrientes & 0,00 & 28,80 & 18,43 & 63,71 & 82,80 & 121,05 & 60,11 & 128,18 & 147,97 \\
\hline TOTAL DE INGRESOS CORRIENTES & 30,83 & 70,54 & 73,69 & 93,02 & 99,14 & 135,09 & 91,93 & 168,38 & 188,77 \\
\hline Gastos corrientes & 138,36 & 204,83 & 321,36 & 357,77 & 471,06 & 648,82 & 688,83 & 874,08 & $1.226,24$ \\
\hline Gastos de consumo & 137,45 & 204,18 & 321,36 & 357,77 & 471,06 & 648,82 & 688,83 & 874,08 & $1.226,24$ \\
\hline Rentas de la propiedad & 0,91 & 0,66 & 0,00 & 0,00 & 0,00 & 0,00 & 0,00 & 0,00 & 0,00 \\
\hline Prestaciones de la seguridad social & 0,00 & 0,00 & 0,00 & 0,00 & 0,00 & 0,00 & 0,00 & 0,00 & 0,00 \\
\hline Otras pérdidas & 0,00 & 0,00 & 0,00 & 0,00 & 0,00 & 0,00 & 0,00 & 0,00 & 0,00 \\
\hline Transferencias corrientes & 0,00 & 0,00 & 0,00 & 0,00 & 0,00 & 0,00 & 0,00 & 0,00 & 0,00 \\
\hline A clasificar & 0,00 & 0,00 & 0,00 & 0,00 & 0,00 & 0,00 & 0,00 & 0,00 & 0,00 \\
\hline TOTAL DE GASTOS CORRIENTES & 138,36 & 204,83 & 321,36 & 357,77 & 471,06 & 648,82 & 688,83 & 874,08 & $1.226,24$ \\
\hline RESULTADO ECONOM. Ahorro (Des ahd & $-107,53$ & $-134,30$ & $-247,67$ & $-264,75$ & $-371,92$ & $-513,72$ & $-596,90$ & $-705,70$ & $-1.037,47$ \\
\hline \multicolumn{10}{|c|}{\begin{tabular}{|l|l|} 
CUENTA DE CAPITAL & \\
\end{tabular}} \\
\hline Recursos de capital & 3,00 & 0,55 & 0,55 & 0,55 & 0,55 & 0,37 & 0,37 & 0,00 & 0,00 \\
\hline Recursos propios de capital & 0,00 & 0,00 & 0,00 & 0,00 & 0,00 & 0,00 & 0,00 & 0,00 & 0,00 \\
\hline Transferencias de capital & 3,00 & 0,55 & 0,55 & 0,55 & 0,55 & 0,37 & 0,37 & 0,00 & 0,00 \\
\hline Disminución de Inv. Financiera & 0,00 & 0,00 & 0,00 & 0,00 & 0,00 & 0,00 & 0,00 & 0,00 & 0,00 \\
\hline TOTAL DE RECURSOS DE CAPITAL & 3,00 & 0,55 & 0,55 & 0,55 & 0,55 & 0,37 & 0,37 & 0,00 & 0,00 \\
\hline Gastos de capital & 4,73 & 2,77 & 1,40 & 9,46 & 65,35 & 43,89 & 2,36 & 0,01 & 1,39 \\
\hline Inversión real directa & 4,73 & 2,77 & 1,40 & 9,46 & 65,35 & 43,89 & 2,36 & 0,01 & 1,39 \\
\hline Transferencias de capital & 0,00 & 0,00 & 0,00 & 0,00 & 0,00 & 0,00 & 0,00 & 0,00 & 0,00 \\
\hline Inversión financiera & 0,00 & 0,00 & 0,00 & 0,00 & 0,00 & 0,00 & 0,00 & 0,00 & 0,00 \\
\hline A clasificar & 0,00 & 0,00 & 0,00 & 0,00 & 0,00 & 0,00 & 0,00 & 0,00 & 0,00 \\
\hline TOTAL GASTOS DE CAPITAL & 4,73 & 2,77 & 1,40 & 9,46 & 65,35 & 43,89 & 2,36 & 0,01 & 1,39 \\
\hline Contrib. Para Financ. Corrientes & 109,26 & 140,83 & 260,03 & 296,38 & 437,50 & 575,63 & 632,40 & 814,37 & $1.154,84$ \\
\hline Contrib. Para Financ. Corrientes Reintegra & 0,00 & 0,00 & 0,00 & 0,00 & 0,00 & 0,00 & 0,00 & 0,00 & 0,00 \\
\hline Contrib. Para Financ. De Capital & 0,00 & 0,16 & 0,00 & 6,74 & 63,08 & 42,09 & 0,00 & 0,00 & 0,00 \\
\hline Contrib. Para Financ. Capital Reintegrable & 0,00 & 0,00 & 0,00 & 0,00 & 0,00 & 0,00 & 0,00 & 0,00 & 0,00 \\
\hline TOTAL CONTRIBUCIONES FIGURATIVA & 109,26 & 140,98 & 260,03 & 303,12 & 500,58 & 617,72 & 632,40 & 814,37 & $1.154,84$ \\
\hline Gastos Figurativos p/ Transac. Corrientes & 0,00 & 0,00 & 0,00 & 0,00 & 0,00 & 0,00 & 0,00 & 0,00 & 0,00 \\
\hline Gastos Figurativos p/ Transac. Corrientes & 0,00 & 0,00 & 0,00 & 0,00 & 0,00 & 0,00 & 0,00 & 0,00 & 0,00 \\
\hline Gastos Figurativos p/ Transac. De Capital & 0,00 & 0,00 & 0,00 & 0,00 & 0,00 & 0,00 & 0,00 & 0,00 & 0,00 \\
\hline Gastos Figurativos p/ Transac. De Capital & 0,00 & 0,00 & 0,00 & 0,00 & 0,00 & 0,00 & 0,00 & 0,00 & 0,00 \\
\hline TOTAL GASTOS FIGURATIVOS & 0,00 & 0,00 & 0,00 & 0,00 & 0,00 & 0,00 & 0,00 & 0,00 & 0,00 \\
\hline NECESIDAD DE FINANCIAMIENTO & 0,00 & 4,46 & 12,89 & 29,46 & 63,86 & 60,48 & 33,52 & 108,65 & 115,99 \\
\hline \multicolumn{10}{|l|}{ CUENTA DE FINANCIAMIENTO } \\
\hline Fuentes Financieras & 0,00 & 0,00 & 0,00 & 0,00 & 0,00 & 0,00 & 0,00 & 0,00 & 0,00 \\
\hline Disminución de la Inv. Financiera & 0,00 & 0,00 & 0,00 & 0,00 & 0,00 & 0,00 & 0,00 & 0,00 & 0,00 \\
\hline Endeudamiento Público e Increm. De O. Pa & 0,00 & 0,00 & 0,00 & 0,00 & 0,00 & 0,00 & 0,00 & 0,00 & 0,00 \\
\hline IX TOTAL FUENTES FINANCIERAS & 0,00 & 0,00 & 0,00 & 0,00 & 0,00 & 0,00 & 0,00 & 0,00 & 0,00 \\
\hline Contrib. Para Aplicaciones Financieras & 0,00 & 0,00 & 0,00 & 0,00 & 0,00 & 0,00 & 0,00 & 0,00 & 0,00 \\
\hline Contrib. Para Aplicaciones Financieras Re & 0,00 & 0,00 & 0,00 & 0,00 & 0,00 & 0,00 & 0,00 & 0,00 & 0,00 \\
\hline X TOTAL CONTRIBUCIONES FIGURATIV & 0,00 & 0,00 & 0,00 & 0,00 & 0,00 & 0,00 & 0,00 & 0,00 & 0,00 \\
\hline \begin{tabular}{|l|l|} 
Aplicaciones Financieras \\
\end{tabular} & 0,00 & 4,46 & 12,89 & 29,46 & 63,86 & 60,48 & 33,52 & 108,65 & 115,99 \\
\hline Inversión financiera & 0,00 & 0,00 & 0,00 & 0,00 & 0,00 & 0,00 & 0,00 & 0,00 & 0,00 \\
\hline Amort. De la Deuda y Dism. De O. Pasivos & 0,00 & 0,00 & 0,00 & 0,00 & 0,00 & 0,00 & 0,00 & 0,00 & 0,00 \\
\hline Dism. De O. Pasivos - Recursos Afectado & 0,00 & 4,46 & 12,89 & 29,46 & 63,86 & 60,48 & 33,52 & 108,65 & 115,99 \\
\hline XI TOTAL APLICACIONES FINANCIERAS & 0,00 & 4,46 & 12,89 & 29,46 & 63,86 & 60,48 & 33,52 & 108,65 & 115,99 \\
\hline Gastos Figurativos p/ Transac. Financiera & 0,00 & 0,00 & 0,00 & 0,00 & 0,00 & 0,00 & 0,00 & 0,00 & 0,00 \\
\hline Gastos Figurativos p/ Transac. Financiera & 0,00 & 0,00 & 0,00 & 0,00 & 0,00 & 0,00 & 0,00 & 0,00 & 0,00 \\
\hline XII TOTAL GASTOS FIGURATIVOS & 0,00 & 0,00 & 0,00 & 0,00 & 0,00 & 0,00 & 0,00 & 0,00 & 0,00 \\
\hline FINANCIAMIENTO NETO & 0,00 & 0,00 & 0,00 & 0,00 & 0,00 & 0,00 & 0,00 & 0,00 & 0,00 \\
\hline
\end{tabular}

